Universidad de Lima

Facultad de Ciencias Empresariales y Económicas

Carrera de Economía

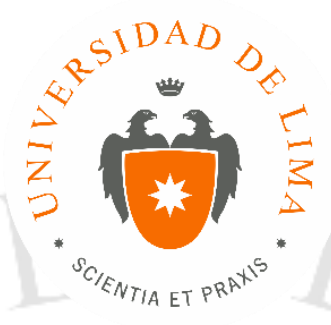

\title{
ANÁLISIS DE INDICADORES DE VULNERABILIDAD FINANCIERA PARA EL CASO PERUANO 2007 - 2018
}

Trabajo de suficiencia profesional para optar el Título Profesional de Economista

Sustentación de caso

Kathleen Yolanda Loli Trigoso

Código 20100627

\section{Asesor}

Pavel Omar Hernández Bracamonte

Lima - Perú

Diciembre de 2018 


\section{ANÁLISIS DE INDICADORES DE VULNERABILIDAD FINANCIERA PARA EL CASO PERUANO 2007 - 2018}




\section{TABLA DE CONTENIDO}

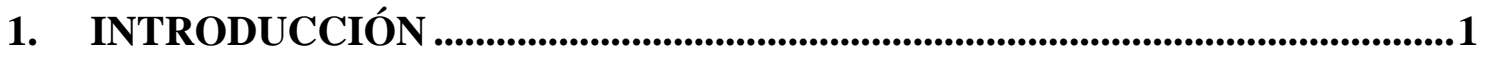

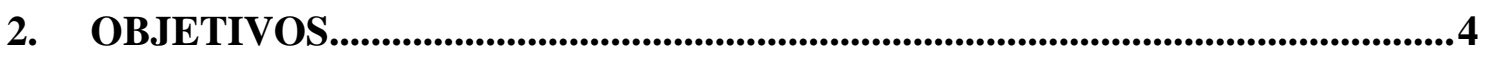

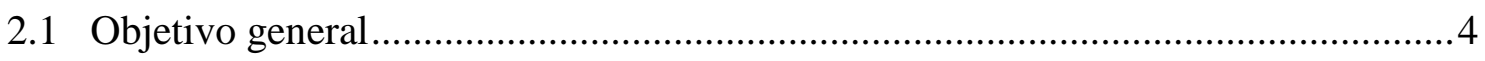

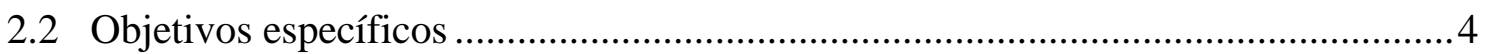

3. PREGUNTAS DE INVESTIGACIÓN ..................................................................5

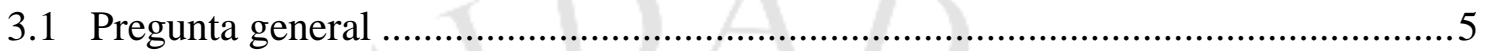

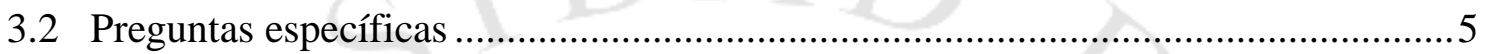

4. METODOLOGÍA DE RECOLECCIÓN DE LA INFORMACIÓN ..................6

5. METODOLOGÍA DE ANÁLISIS DE LA INFORMACIÓN ............................10

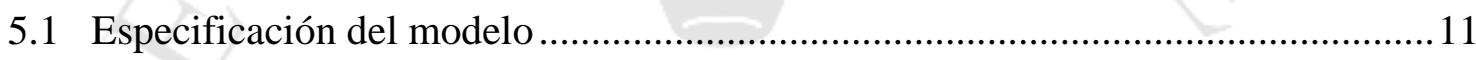

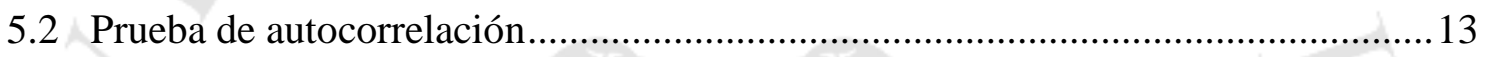

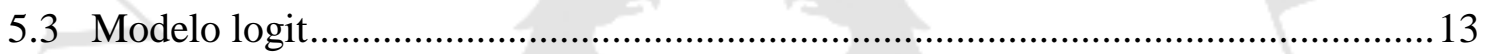

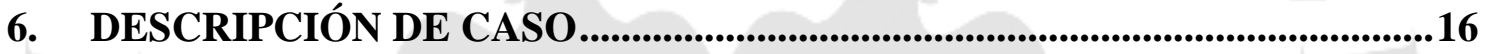

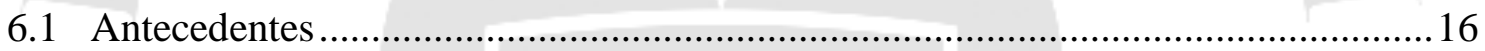

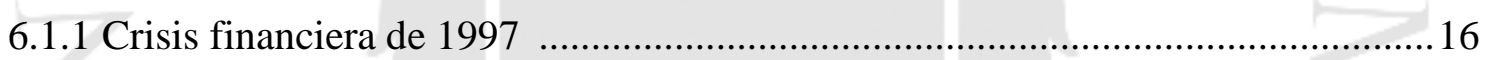

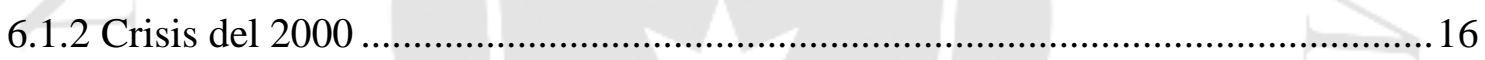

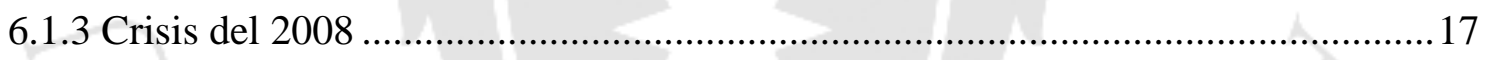

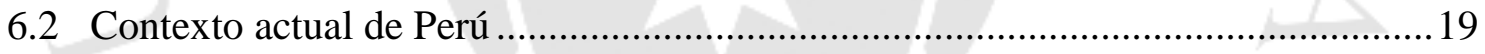

6.3 Variables consideradas en la medición de vulnerabilidad financiera .......................24

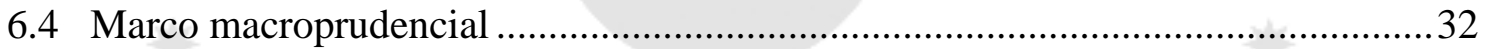

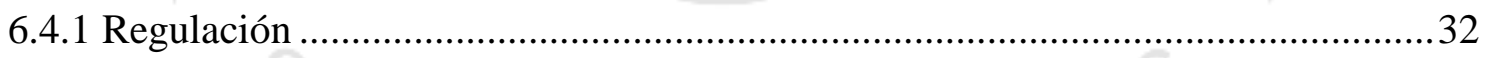

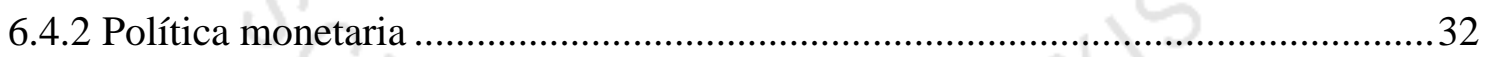

7. ANÁLISIS Y DISCUSIÓN DE RESULTADOS..................................................35

RECOMENDACIONES ..............................................................................39

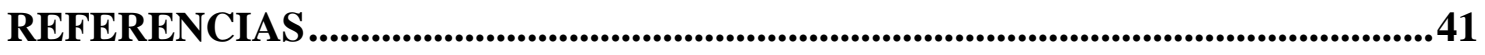

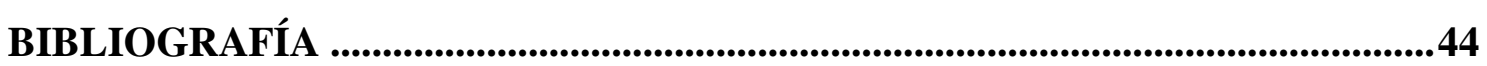




\section{ÍNDICE DE TABLAS}

Tabla 4.1 Medición de indicadores de vulnerabilidad financiera - sector bancario.........9

Tabla 5.1 Indicadores de vulnerabilidad financiera - sector bancario ........................... 11

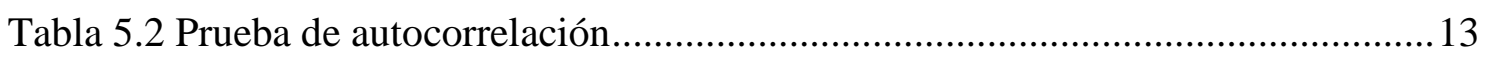

Tabla 5.3 Índice de medición de vulnerabilidad financiera.......................................... 14

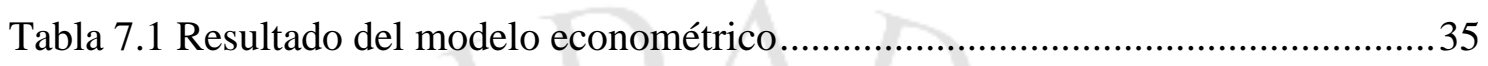

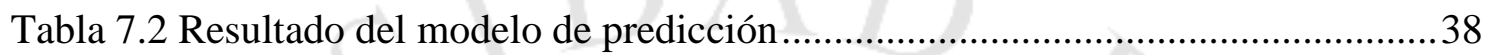




\section{ÍNDICE DE FIGURAS}

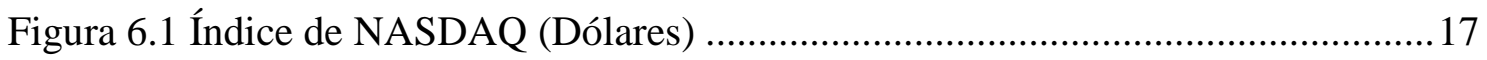

Figura 6.2 Variación anual del Producto Bruto Interno de Perú $(\%)$..............................20

Figura 6.3 Evolución de las Reservas Internacionales Netas de Perú (Millones de dólares)

Figura 6.4 Reservas Internacionales Netas respecto del PBI de Sudamérica, 2017 (\%) 22

Figura 6.5 Evolución del Resultado Económico del Sector Público no Financiero respecto

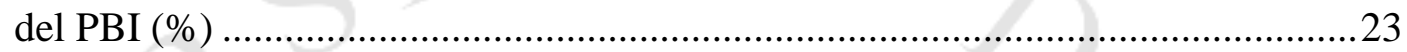

Figura 6.6 Estructura del sistema financiero, según tipo de cuenta del balance (\%)......24

Figura 6.7 Nivel de morosidad del sistema bancario (Cartera de créditos atrasados / Total de créditos, \%)

Figura 6.8 Grado de cobertura del sistema bancario (Provisiones constituidas / Cartera de

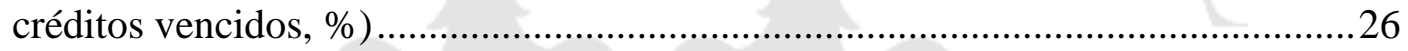

Figura 6.9 Variación de créditos en dólares del sistema bancario $(\%)$..........................2. 28

Figura 6.10 Variación de depósitos en dólares del sistema bancario (\%) .....................29

Figura 6.11 Ratio de liquidez en moneda nacional del sistema bancario (Promedio de saldos activos líquidos en Soles / Promedio de saldos de pasivos de corto plazo en

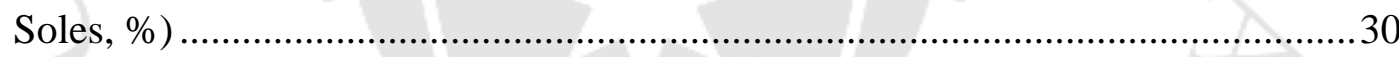

Figura 6.12 Evolución de la rentabilidad sobre patrimonio de los bancos en Perú (Utilidad neta anualizada / Patrimonio promedio, \%) ........................................................... 31

Figura 6.13 Evolución de la Tasa de Referencia de la política monetaria del BCRP (\%) .34

Figura 7.1 Indicador de vulnerabilidad financiera .37 


\section{ÍNDICE DE ANEXOS}

Anexo 1: Resultado del modelo econométrico logit para la vulnerabilidad financiera..46 Anexo 2: Resultado de la predicción de probabilidad de vulnerabilidad financiera ......47

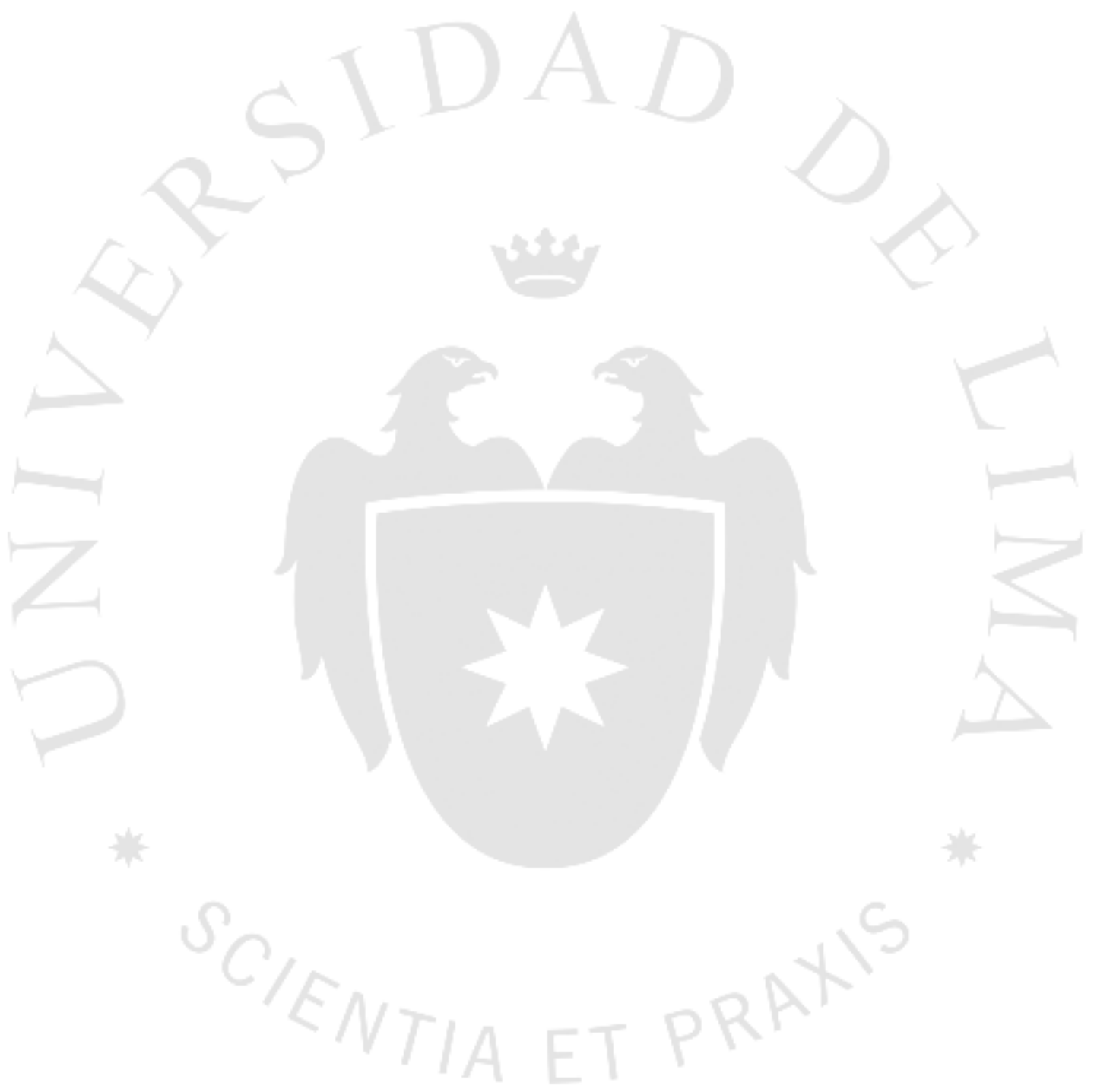




\section{INTRODUCCIÓN}

Durante los últimos años, en las economías emergentes y desarrolladas, se ha presenciado una gran profundización en los mercados financieros; asociada al desarrollo de la tecnología. Esto acentúa la complejidad de la interacción entre los principales agentes y el sistema financiero. En el Perú, dicho sistema está conformado por: banca múltiple, empresas financieras, instituciones microfinancieras no bancarias (cajas municipales, cajas rurales y EDPYMES), bancos de inversión, entidades estatales (COFIDE, Agrobanco y MiVivienda) y empresas especializadas (arrendamiento).

La citada complejidad eleva el nivel de competitividad, ya que se encuentra en mejor posición para responder ante el desenvolvimiento del mercado y adaptarse a la evolución del mismo, lo cual sostiene el crecimiento de la economía. Así lo menciona el ex director gerente del Fondo Monetario Internacional (FMI):

A medida que las políticas macroeconómicas se han vuelto más creíbles y crece la confianza de que la inflación seguirá siendo baja, aumenta la demanda de servicios financieros. A medida que crecen los mercados financieros, aumenta la disponibilidad de crédito y se fomenta un crecimiento no inflacionario más rápido. Y a medida que los mercados financieros se vuelven más sofisticados y se facilitan las tareas de gestionar y cubrir riesgos, las economías pueden hacer frente a la volatilidad más eficazmente. (de Rato y Figaredo, 2007)

Sin embargo, también se pueden identificar deficiencias durante dicha evolución, las cuales generaron turbulencias denominadas vulnerabilidad. Esta, puede desencadenar crisis financieras, como las ocurridas en 1997 (Asia), 2000 (Dotcom) y 2008 (subprime); y en muchas ocasiones, puede producir un "efecto contagio", definido por Juan José Toribio (2012) como escenario en el que la inestabilidad financiera o de actividad productiva, con origen en un lugar determinado, trasciende de forma significativa a otras economías que inicialmente no presentan las mismas situaciones.

La vulnerabilidad financiera se puede medir a través de indicadores del sistema financiero, los cuales se rigen por las políticas monetarias y de regulación. Como mencionan Berges, Manzano y Valero (2011), el objetivo de la supervisión y regulación 
es el de reducir la vulnerabilidad financiera, con el objetivo de impedir que la crisis vuelva a suceder a futuro; como medida de precaución.

El estudio sobre la vulnerabilidad financiera es relevante tanto para Latinoamérica como para Perú, debido a la profundización financiera actual. Y, en este contexto, aumenta la importancia de fortaleza de los bancos para hacer frente ante situaciones de crisis. El presente caso se desarrolla para poder conocer los puntos débiles del sistema bancario, ya que las últimas crisis surgieron a partir de fallas en la estructura de los bancos.

De ahí que, la vulnerabilidad financiera sea revisada por el FMI (en su Global Financial Stability Report), así como en sus informes del Article IV Consultation, que realiza a países miembros y en los cuales evalúa políticas económicas y financieras para reducir la vulnerabilidad a la crisis y buscar el crecimiento sostenido; dando una visión tanto macroeconómica como financiera. También, es evaluada cada seis meses por el Banco Central de Reserva del Perú (en su Reporte de Estabilidad Financiera), que busca identificar los riesgos que afecten la estabilidad financiera para tomar medidas de prevención, para atenuar su impacto en el sistema monetario y financiero.

El informe que se presenta a continuación se aplica al caso peruano para el intervalo temporal del 2007 - 2018; y se busca analizar la vulnerabilidad financiera para lo cual se trabaja con variables del sistema bancario. El contenido del informe tiene la siguiente estructura: en primer lugar, se presenta la descripción del objetivo general, que es el del análisis de indicadores que midan la vulnerabilidad financiera, y sus objetivos específicos. En segundo lugar, se proponen las preguntas de investigación, en función de las variables que buscan explicar la vulnerabilidad financiera.

Luego, en tercer lugar, se presenta la metodología de recolección de la información, en donde se indican las variables utilizadas, así como sustento para emplearlas. A continuación, en cuarto lugar, se presenta la metodología de análisis de la información, que explica la selección del modelo y sus variables significativas, los tratamientos aplicados, la racionalidad de los mismos, así como resultados de modelos previos. 
Más adelante, en quinto lugar, se describe el caso, se detalla los antecedentes de la situación actual, la relación entre los indicadores y los casos de crisis financieras, contextualizando las variables escogidas y medidas empleadas por las entidades reguladoras. Seguidamente, en sexto lugar, se muestra el análisis y presentación de resultados para el caso peruano, evaluando un modelo de estimación de variables sobre la vulnerabilidad financiera. Por último, se proponen recomendaciones a aplicar para la economía peruana, a nivel bancario y macroeconómico.

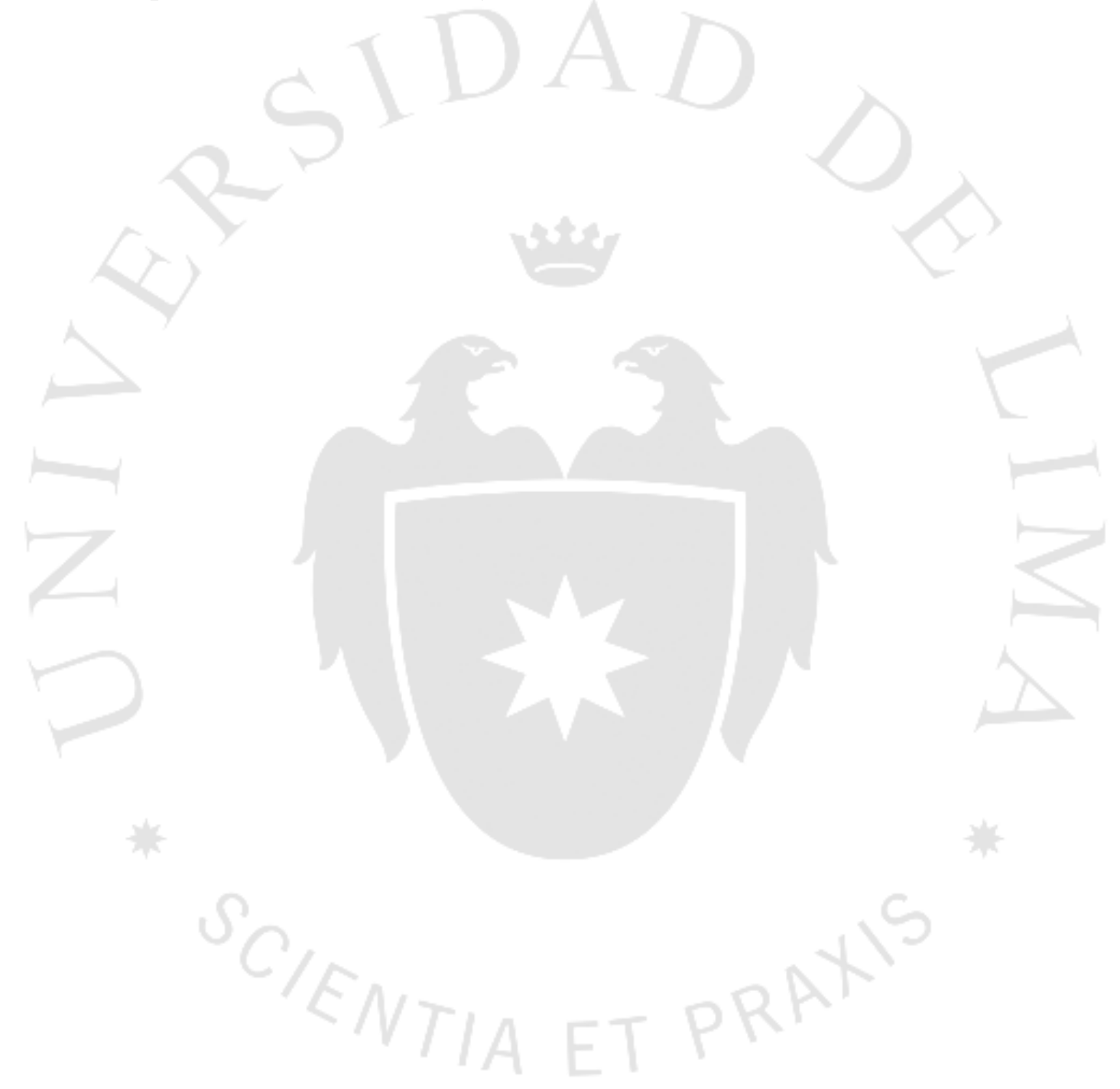




\section{OBJETIVOS}

\subsection{Objetivo general}

Proponer un conjunto de indicadores que mida la vulnerabilidad financiera para el sector bancario peruano, para el período 2007 - 2018.

\subsection{Objetivos específicos}

- Revisar el escenario actual del país, a través de la presentación de la evolución de los indicadores macroeconómicos; así como también de políticas monetarias y de regulación para situar el contex to actual.

- Utilizando la metodología de un estudio anterior de vulnerabilidad financiera, junto con la del Fondo Monetario Internacional y Banco Central de Reserva del Perú, proponer variables que midan la vulnerabilidad financiera acorde a la situación actual del sector bancario.

- Comprender la relación y nivel de significancia de dichas variables; determinadas por un modelo, con análisis y pruebas que evalúen la data histórica; evaluando el modelo de predicción que arroje niveles correctos de estimación de las variables endógenas sobre el indicador de vulnerabilidad. 


\section{PREGUNTAS DE INVESTIGACIÓN}

Entre las principales interrogantes sobre el estudio de caso; se tienen las siguientes respecto de los objetivos:

\subsection{Pregunta general}

- ¿Existe un conjunto óptimo de indicadores que pueda medir la vulnerabilidad financiera? ¿Este conjunto puede aplicarse al sector bancario peruano durante el período $2007-2018$ ?

\subsection{Preguntas específicas}

- ¿Cuál es el contexto actual en el que se encuentra el país? ¿Cuáles son las teorías que explican cada variable como influyente sobre la vulnerabilidad financiera? ¿Cuál es la situación del sistema de regulación y las políticas monetarias aplicadas actualmente?

- ¿Cuáles son los indicadores que se consideran para la medición de la vulnerabilidad financiera para Perú? ¿Cuál es el modelo econométrico que se adapta a la evaluación de vulnerabilidad?

- ¿Cómo se explica la relación y nivel de significancia de los indicadores sobre la vulnerabilidad financiera? ¿Las variables mencionadas en el estudio de caso presentan un papel importante para la predicción del indicador de vulnerabilidad financiera? 


\section{METODOLOGÍA DE RECOLECCIÓN DE LA INFORMACIÓN}

Principalmente, se consideran variables del sector bancario para un modelo econométrico de predicción de una crisis.

Las siguientes publicaciones facilitaron la identificación de variables y la explicación de cada una de ellas respecto de la estabilidad financiera:

- Global Financial Stability Report (GFSR): Reporte publicado con periodicidad semestral (abril y octubre) por el FMI para sus países miembros; en donde precisa los riesgos al corto plazo que enfrentan la estabilidad de las economías globales ante sus condiciones financieras.

- Reporte de Estabilidad Financiera: Publicado por el Banco Central de Reserva del Perú, con periodicidad semestral (mayo y noviembre), en donde evalúa los riesgos y las políticas macroeconómicas a tomar en consideración a la estabilidad monetaria y financiera, como soporte del crecimiento sostenible del país.

A partir de estos documentos, los indicadores bancarios considerados para el presente estudio sobre vulnerabilidad financiera son los siguientes, detallando las fuentes de información:

- $\quad$ Medición de Calidad de Créditos

- Morosidad: Nivel de créditos que presentan incumplimiento de pago al vencimiento en las entidades bancarias, a través de la medición de créditos atrasados / créditos directos; en términos porcentuales. Fuente de información: Secundaria - obtenida de la Superintendencia de Banca, Seguros y AFP (2007 - 2018).

La variable presenta significancia sobre el indicador de vulnerabilidad ya que representa el grado de atrasos en los créditos de los bancos. Se espera una relación directa sobre la vulnerabilidad. Es decir, que una mayor morosidad se asocie a un mayor grado de vulnerabilidad financiera y viceversa. 
- Cobertura: Nivel de provisiones que reservan los bancos respecto del total de cartera atrasada, se mide como: provisiones / créditos atrasados; en términos porcentuales. Fuente de información: Secundaria - obtenida de la Superintendencia de Banca, Seguros y AFP (2007 - 2018).

La variable presenta relevancia sobre el indicador de vulnerabilidad ya que representa el nivel de protección que se mantiene sobre los créditos atrasados de los bancos. Se espera una relación inversa. Esto significa que cuando la proporción de reservas respecto de la cartera morosa es mayor, la vulnerabilidad financiera del sistema es menor, porque éste tiene más provisiones para hacer frente a situaciones de stress.

- Variación de créditos en dólares: Mide fluctuaciones de los créditos en moneda extranjera, a través de la diferencia de créditos directos del período actual y el anterior / créditos directos del período anterior; en términos porcentuales. Fuente de información: Secundaria obtenida de la Superintendencia de Banca, Seguros y AFP (2007 2018).

La variable presenta importancia sobre el indicador de vulnerabilidad ya que manifiesta la reacción sobre la variación en las tasas de interés del mercado, se espera una relación directa sobre la vulnerabilidad dado que, ante una mayor variación de los créditos en dólares, a mayor vulnerabilidad financiera se expone el sector bancario.

- Medición de Liquidez

- Variación de depósitos en dólares: Mide la fluctuación del total de depósitos en moneda extranjera, a través de diferencia de depósitos entre el período actual y anterior / depósitos del período anterior; en términos porcentuales. Fuente de información: Secundaria - obtenida de la Superintendencia de Banca, Seguros y AFP (2007 - 2018).

La variable presenta relevancia sobre el indicador de vulnerabilidad ya que manifiesta la respuesta ante la variación en las tasas del 
mercado y la cobertura de las empresas. Se espera una relación directa; ya que, ante una mayor variación de los depósitos en dólares, el sector bancario podría afrontar mayor vulnerabilidad financiera.

- Grado de Liquidez: Mide la capacidad de las entidades bancarias de afrontar requerimientos de fondos líquidos, manteniendo fondos transaccionales. Medido como el saldo promedio de activos líquidos / saldo promedio de pasivos del corto plazo, ambos en moneda nacional; en términos porcentuales. Fuente de información: Secundaria - obtenida de la Superintendencia de Banca, Seguros y AFP (2007 - 2018).

La variable presenta relevancia sobre el indicador de vulnerabilidad ya que manifiesta el grado para afrontar los pasivos corrientes de los bancos en moneda nacional. Se espera una relación inversa ya que ante un mayor nivel de disposición de fondos líquidos (liquidez), se asociaría a un escenario de menor vulnerabilidad financiera.

- Medición de Rentabilidad

○ Nivel de Rentabilidad: Mide la eficiencia de generación de utilidades con la inversión de los accionistas (patrimonio), a través del ROE (utilidad neta / patrimonio); términos porcentuales. Fuente de información: Secundaria - obtenida de la Superintendencia de Banca, Seguros y AFP (2007 - 2018).

La variable presenta importancia sobre el indicador de vulnerabilidad ya que manifiesta el nivel de rendimiento del patrimonio respecto de la utilidad de los bancos. Se espera una relación inversa sobre la vulnerabilidad ya que, ante una mayor rentabilidad, como grado de posicionamiento y fortaleza de los bancos, se reflejaría en un menor nivel de vulnerabilidad financiera.

Con estas variables, se correrá un modelo econométrico logit para entender y explicar el efecto de dichas variables sobre una crisis bancaria para el caso peruano. Con el modelo se busca calcular el grado de estimación de las variables sobre el indicador de vulnerabilidad. 
Tabla 4.1

Medición de indicadores de vulnerabilidad financiera - sector bancario

\begin{tabular}{|c|l|}
\hline Variable & \multicolumn{1}{|c|}{ Medición } \\
\hline Morosidad & Morosidad / total créditos \\
\hline Cobertura & Provisiones/ créditos atrasados \\
\hline Variación de Créditos en dólares & $\triangle$ Créditos directos en ME / créditos directos en ME $(\mathrm{t}-1, \mathrm{t})$ \\
\hline Variación de Depósitos en dólares & $\triangle$ Depósitos en ME / depósitos en ME $(\mathrm{t}-1, \mathrm{t})$ \\
\hline Liquidez en soles & Ratio de liquidez en MN total banca \\
\hline Rentabilidad & Utilidad neta anualizada / patrimonio promedio \\
\hline
\end{tabular}

Elaboración Propia

Cabe resaltar que la información recopilada corresponde a todas las entidades bancarias, que a setiembre 2018 se encuentra conformada por 16 bancos. Según detalla el Banco Central de Reserva (BCRP), estos son: Banco de Comercio, Banco de Crédito del Perú (BCP), Banco Interamericano de Finanzas (BanBif), Banco Pichincha, BBVA Continental, Citibank Perú, Interbank, MiBanco, Scotiabank del Perú, Banco GNB Perú, Banco Falabella, Banco Ripley, Banco Santander Perú, Banco Azteca, Banco Cencosud e ICBC Perú Bank. 


\section{METODOLOGÍA DE ANÁLISIS DE LA INFORMACIÓN}

Basados en el trabajo de investigación de Luis Allaín (2006), sobre los indicadores de vulnerabilidad financiera para el sistema bancario en América Latina aplicado a Perú, se consideran variables que aporten a la evaluación de la vulnerabilidad total, compuesta por tres frentes de vulnerabilidad: financiera, externa e interna.

Dichas variables coinciden con las consideradas en el informe Global Financial Stability Report del FMI, que incluye indicadores de vulnerabilidad financiera y externa, para 184 países. Estas variables influyen sobre la estabilidad y fortalecimiento financiero, sobre la base de su aporte al crecimiento sostenido, nivel de empleo óptimo y reducción de pobreza, a partir de políticas monetarias coordinadas en conjunto por sus países miembros.

Asimismo, las variables son incluidas en el Reporte de Estabilidad Financiera, del Banco Central de Reserva del Perú (BCRP), desde la perspectiva de fortalecimiento del sistema financiero y sus principales indicadores.

Para el análisis del caso, primero, se revisarán los antecedentes de crisis financieras mundiales, se exploran las causas que las ocasionaron, sus consecuencias, los indicadores que reflejaron dichas crisis y las medidas que se tomaron para poder atenuarlas.

Luego, se muestra el contexto macroeconómico actual de Perú, para poder evaluar la posición de vulnerabilidad financiera, incluyendo factores externos provenientes del entorno internacional.

Posteriormente, se muestra la información tomada de la Superintendencia de Banca, Seguros y AFP (SBS) de los principales indicadores de los bancos, los cuales evidencian la situación financiera ante una posible crisis bancaria. Luego, se analiza la trayectoria de variables que explican la vulnerabilidad financiera desde la perspectiva macroeconómica y microeconómica, incluyendo las medidas tomadas por parte de las entidades reguladoras. 
Luego, se propone un modelo para evaluar la vulnerabilidad financiera, considerando data de la crisis financiera del 2008, para comprobar las variables que mantienen relevancia.

Los indicadores considerados se muestran en el siguiente cuadro:

Tabla 5.1

Indicadores de vulnerabilidad financiera - sector bancario

\begin{tabular}{|c|l|l|l|l|}
\hline Variable & Definición & Periodicidad & Unidades & Fuente \\
\hline MORA & Morosidad / total créditos & Mensual: 2007-2018 & Porcentual & SBS \\
\hline COBER & Provisiones/ créditos atrasados & Mensual: 2007-2018 & Porcentual & SBS \\
\hline VAR_CRED_ME & $\begin{array}{l}\text { Variación de créditos directos en } \\
\text { ME }\end{array}$ & Mensual: 2007-2018 & Porcentual & SBS \\
\hline VAR_DEP_ME & Variación de depósitos en ME & Mensual: 2007-2018 & Porcentual & SBS \\
\hline LIQ_MN & $\begin{array}{l}\text { Ratio de liquidez en MN total } \\
\text { banca }\end{array}$ & Mensual: 2007-2018 & Porcentual & SBS \\
\hline ROEA & $\begin{array}{l}\text { Utilidad neta anualizada / } \\
\text { patrimonio promedio }\end{array}$ & Mensual: 2007-2018 & Porcentual & SBS \\
\hline
\end{tabular}

Elaboración Propia

El modelo propuesto es de tipo probabilístico (logit) para evaluar la implicancia de las variables y poder evaluar un modelo de predicción sobre el indicador de vulnerabilidad financiera. La incorporación de probabilidades agrega valor desde que permite:

Centrarse en el estudio de los modelos de elección discreta binaria, esto es: al individuo se le plantea tomar una decisión de entre únicamente dos posibilidades mutuamente excluyentes. La variable endógena $\mathrm{Y}$ de estos modelos adopta dos únicos valores numéricos discretos, normalmente 0 y 1; de modo que, si el sujeto se decanta por la ocurrencia del suceso objeto de estudio entonces $\mathrm{Y}$ toma el valor 1 , y 0 , si no es así. (Ordan, Melgar y Rubio, 2010, p. 224)

\subsection{Especificación del modelo}

Las variables iniciales a emplear se encuentran en el horizonte temporal de enero de 2007 a setiembre de 2018; con periodicidad mensual, expresadas todas en términos porcentuales. Son mencionadas a continuación:

- Morosidad (Mora) 
- Cobertura (Cober)

- Variación de créditos en dólares (Var_Cred_ME)

- Variación de depósitos en dólares (Var_Dep_ME)

- Ratio de liquidez de soles (Liq_MN)

- $\quad$ Nivel de rentabilidad patrimonial (ROEA)

Para evaluar la vulnerabilidad financiera, se plantea el siguiente modelo:

$$
\begin{gathered}
\text { Vul_Fin }_{\mathrm{i}}=\widehat{\alpha}+\widehat{\beta}_{1} * \operatorname{Mora}_{\mathrm{i}}+\widehat{\beta}_{2} * \text { Cober }_{\mathrm{i}}+\widehat{\beta}_{3} * \operatorname{Var}_{-} \text {Cred_ME } \\
+ \\
+\widehat{\beta}_{5} * \widehat{\beta}_{4} * \operatorname{Liq}_{-} \text {Var }_{\mathrm{i}}+\widehat{\beta}_{6} * \mathrm{ROEA}_{\mathrm{i}}
\end{gathered}
$$

Los coeficientes del modelo reflejan la relación que existe entre el índice de vulnerabilidad financiera (variable endógena), y las variables exógenas.

- El coeficiente $\widehat{\beta}_{1}$ representa el efecto de la morosidad del sector bancario sobre la probabilidad de crisis (alerta de que aparezca la misma). Se espera que dicho coeficiente tenga una relación positiva con el indicador de vulnerabilidad.

- El coeficiente $\hat{\beta}_{2}$ representa el efecto del nivel de cobertura del sector bancario sobre la probabilidad de crisis (alerta de que aparezca la misma). Se espera que dicho coeficiente tenga una relación negativa con el indicador de vulnerabilidad.

- El coeficiente $\widehat{\beta}_{3}$ representa el efecto de la variación de créditos en moneda extranjera de los bancos sobre la probabilidad de crisis (alerta de que aparezca la misma). Se espera que dicho coeficiente tenga una relación positiva con el indicador de vulnerabilidad.

- El coeficiente $\widehat{\beta}_{4}$ representa el efecto de la variación de depósitos en moneda extranjera de los bancos sobre la probabilidad de crisis (alerta de que aparezca la misma). Se espera que dicho coeficiente tenga una relación positiva con el indicador de vulnerabilidad.

- El coeficiente $\widehat{\beta}_{5}$ representa el efecto del nivel de liquidez del sector bancario sobre la probabilidad de crisis (alerta de que aparezca la misma). Se espera 
que dicho coeficiente tenga una relación negativa con el indicador de vulnerabilidad.

- El coeficiente $\widehat{\beta}_{6}$ representa el efecto de la rentabilidad patrimonial del sector bancario la probabilidad de crisis (alerta de que aparezca la misma). Se espera que dicho coeficiente tenga una relación positiva con el indicador de vulnerabilidad.

\subsection{Prueba de autocorrelación}

En un modelo de tipo series de tiempo, es muy probable que exista autocorrelación entre las variables; a diferencia de los datos de corte transversal que no presentan dicho problema. Se define la autocorrelación como el indicador de relación de dependencia de las variables entre sí.

Se realizó la prueba de correlación en el programa eViews entre las variables principales que miden la vulnerabilidad financiera del sector bancario, detectando que las variables no presentan problemas de correlación entre ellas.

Tabla 5.2

Prueba de autocorrelación

\begin{tabular}{|c|c|c|c|c|c|c|}
\hline & MORA & \multicolumn{1}{c|}{ COBER } & VAR_CRED_ME & VAR_DEP_ME & LIQ_MN & ROEA \\
\hline MORA & 1.000000 & -0.978664 & -0.418406 & -0.196608 & -0.634228 & -0.882820 \\
\hline COBER & -0.978664 & 1.000000 & 0.493346 & 0.193627 & 0.704517 & 0.887102 \\
\hline VAR_CRED_ME & -0.418406 & 0.493346 & 1.000000 & 0.215190 & 0.526834 & 0.313936 \\
\hline VAR_DEP_ME & -0.196608 & 0.193627 & 0.215190 & 1.000000 & 0.078792 & 0.196971 \\
\hline LIQ_MN & -0.634228 & 0.704517 & 0.526834 & 0.078792 & 1.000000 & 0.470474 \\
\hline ROEA & -0.882820 & 0.887102 & 0.313936 & 0.196971 & 0.470474 & 1.000000 \\
\hline
\end{tabular}

Elaboración: Propia

\subsection{Modelo logit}

Se utiliza un modelo de variable dependiente limitada, dado que el modelo de regresión lineal simple supone que el rango de variación de la variable dependiente tome cualquier valor $(-\infty,+\infty)$. Específicamente se emplea el modelo logit, para poder estimar la variable dependiente binaria de vulnerabilidad financiera, que se explica por Wooldridge (2014) como: 
Una variable dependiente binaria es un ejemplo de una variable dependiente limitada (VDL). Una VDL se define en sentido amplio como una variable dependiente cuyo rango de valores está restringido de forma importante. Una variable binaria asume sólo dos valores, el cero y el uno.” (p. 574)

El modelo logit aplica para el caso ya que no existe un índice del grado de vulnerabilidad financiera. Para la medición, se toma las variables 0 (no ocurre) y 1 (sí ocurre); y lo que se trata de hallar es la probabilidad de ocurrencia del indicador de vulnerabilidad financiera.

Si bien existen 2 tipos de modelos de variable limitada (logit y probit); se utiliza el modelo logit ya que "se trata de una función de distribución acumulada para una variable aleatoria logística estándar"; mientras que el modelo probit, no se aplica ya que “es la función de distribución acumulada normal estándar, que se expresa como una integral" (Wooldridge, 2010, p. 576). usualmente se emplea el modelo logit ya que el modelo probit puede mostrar problemas de convergencia, según el tipo de información.

Siguiendo con la metodología de Allaín (2006), se procede con el modelo calculando la media simple de las variables exógenas. De donde, la variable vulnerabilidad financiera (VUL_FIN) tomará los valores de 1 , para eventos donde 3 o más variables muestren comportamiento que pueda incrementar el riesgo de crisis; o de 0 , para comportamiento que no implique riesgo. Se utilizan 3 variables como el mínimo de indicador de vulnerabilidad en un escenario de prevención, sobre un total de 6 variables que componen el modelo.

El índice se construyó utilizando la data mensual conformada desde enero 2007 a setiembre 2018, bajo cálculo de media simple. La data fue recolectada de la información histórica de la SBS (2018).

Tabla 5.3

Índice de medición de vulnerabilidad financiera

\begin{tabular}{|l|c|}
\hline & MEDIA \\
\hline Cobertura & $<203.68$ \\
Mora & $>2.1$ \\
R O E & $<23.25$ \\
Liquidez MN & $<38.42$ \\
Var_Cred_ME & $>0.66$ \\
Var_Dep_ME & $<0.7$ \\
\hline
\end{tabular}

Elaboración propia. 
Lo que se trata de probar con el modelo logit es la probabilidad del evento. Para este caso, la ocurrencia de vulnerabilidad financiera; dentro de los 141 datos. Se dividirán entre 2 grupos:

- $\quad 0$ - No probabilidad de presencia de vulnerabilidad financiera.

- 1 - Probabilidad de ocurrencia de vulnerabilidad financiera.

Es importante indicar que el modelo no predice la ocurrencia del evento, ya que para ello se deberán trabajar con variables estimadas o proyectadas. El modelo indica la estimación del indicador de vulnerabilidad y el grado de precisión de las variables explicativas sobre el indicador mencionado.

Para poder proyectar la probabilidad de ocurrencia de crisis, existe los modelos alerta anticipada, los cuales son elaborados y empleados por bancos centrales e instituciones financieras internacionales, como el FMI, para calcular el riesgo de que se produzca crisis monetarias; y evitarlas a través de medidas correctivas. Sin embargo, a pesar de que los resultados muestren congruencia de estimación de crisis; ante la inexactitud de las predicciones, el FMI debe utilizar este modelo como parte de otros indicadores que componen y apoyan su tarea de supervisión.

Este modelo se estima a partir de proyecciones de las variables definidas; así como a partir del comportamiento de las mismas variables sobre el indicador de vulnerabilidad. 


\section{DESCRIPCIÓN DE CASO}

\subsection{Antecedentes}

Se citan a continuación las crisis financieras más recientes y con mayor impacto en el desenvolvimiento de las economías globales:

\subsubsection{Crisis financiera de 1997}

Se trata de la crisis asiática, que se inició en julio de dicho año. Durante las tres décadas previas, los países del sudeste asiático (Corea, Indonesia, Malasia y Tailandia) mostraron altas tasas de crecimiento, inflación controlada a la baja, y fuertes niveles de exportaciones e inversiones. Sin embargo, la crisis llegó. Se originó en Tailandia (con la devaluación del Baht), que posteriormente ocasionó un "efecto contagio" sobre los demás países. El reporte del FMI lo considera así:

Primero, se produjo una oferta considerable de fondos internacionales a tasas de interés relativamente bajas ya que los inversionistas, en busca de nuevas oportunidades de inversión, trasladaron fuertes cantidades de capital a Asia. Como en todos los ciclos de auge y caída, en un principio los precios de las acciones y los bienes raíces se dispararon, de modo que la región atrajo más fondos aún. No obstante, la asignación interna de estos recursos externos era ineficiente debido a la poca solidez de los sistemas bancarios, la deficiente administración de las empresas y la falta de transparencia del sector financiero. Segundo, los regímenes cambiarios —que, de hecho, eran regímenes de paridad fijadieron a los prestatarios una engañosa sensación de seguridad y los incitaron a asumir deudas en dólares de EE.UU. Tercero, en los países afectados por la crisis, las exportaciones mostraron poco dinamismo a mediados de los años noventa por varias razones, entre ellas, la apreciación del dólar de EE.UU. frente al yen, la devaluación del yuan de China en 1994 y la pérdida de algunos mercados tras la firma del Tratado de Libre Comercio de América del Norte. (Aghevli, 1999, pp. 28-29)

\subsubsection{Crisis del 2000}

Llamada "Crisis de las Dotcom". Se dio cuando algunas empresas empezaron a registrarse en los dominios de Internet (que comenzó a masificarse en 1985, alcanzando millones de registros para 1997) para así crear proyectos con el objetivo de maximizar su rentabilidad. Ello generó interés en inversores para la adquisición de acciones (empresas 
tecnológicas que cotizaban en NASDAQ) y una burbuja debido a la sobrevaloración de estas empresas; por lo que el cambio de las expectativas de los inversores (cuando empezaron a percibir ciertos resultados negativos), desencadenó el desplome de la Bolsa, y con ello el cierre de empresas tecnológicas y grandes pérdidas para los inversores.

Figura 6.1

Índice de NASDAQ (Dólares)

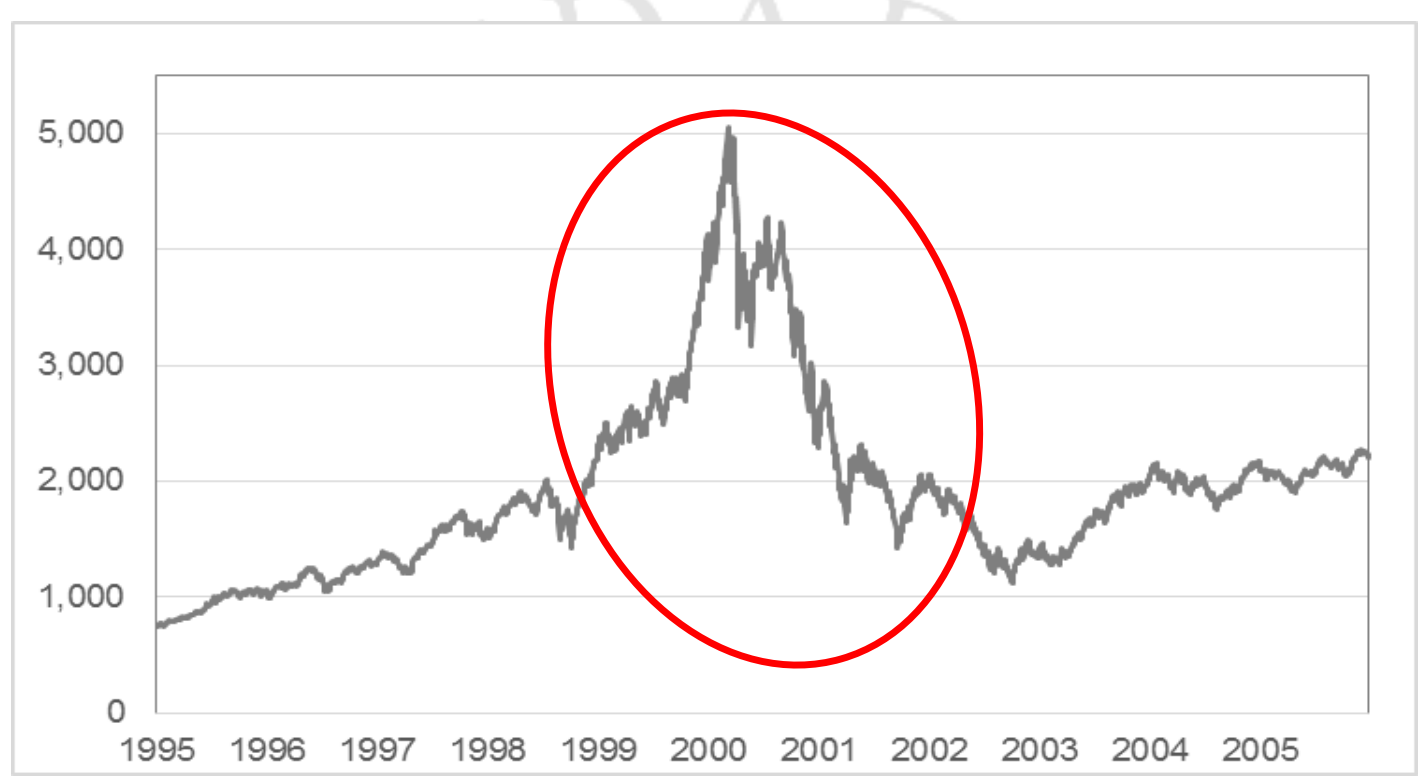

Fuente: Bloomberg (2018)

\subsubsection{Crisis del 2008}

La mayor crisis en Estados Unidos después de la Gran Depresión de 1929. Tuvo origen en el mercado inmobiliario, a partir de que la Reserva Federal de los Estados Unidos (FED) disminuyera su tasa de interés (2002) con el objetivo de lograr la expansión y facilidad para la adquisición de créditos hipotecarios; lo que significó que los créditos sean otorgados sin evaluación prudente (con gran posibilidad de incumplimiento de pagos) sobre las llamadas "hipotecas subprime"; y ello conllevó a una burbuja inmobiliaria (especulación sobre precios de inmuebles, y sobre el costo de los créditos).

Para 2005 - 2006, la FED empezó a elevar la tasa de interés como medida de regulación ante las especulaciones sobre el alza de precios, lo que provocó que la burbuja explotara, y, con ella, el precio de inmuebles se desplomara. Las personas que habían accedido a préstamos optaron por devolver al banco los inmuebles ya que consideraban 
la caída en el valor de los mismos. Esto provocó el default generalizado de los créditos; $\mathrm{y}$, con ello, pérdidas a los bancos.

Cabe resaltar, que, junto con los créditos hipotecarios, iban amarrados otros productos financieros algo más sofisticados, que tampoco contaban con regulación. Esta situación produjo también la bancarrota del banco de inversión más grande: Lehman Brothers.

Sobre esta última crisis, que tuvo mayor impacto a nivel mundial por el efecto contagio, el Banco Central de Reserva del Perú (BCRP, 2009) tomó medidas monetarias tal como lo menciona en su Reporte de Inflación:

Desde setiembre de 2008 el BCRP aplicó medidas para inyectar liquidez por más de 35 mil millones de Soles, casi el 9\% del PBI, para evitar una paralización del crédito y una fuerte depreciación de la moneda con efectos negativos sobre la solidez financiera de las empresas. Se redujeron las tasas de encaje, se implementaron nuevos mecanismos de inyección de liquidez como las Repos a plazos de hasta 1 año, swaps de monedas, recompra de los Certificados de Depósito del BCRP, entre otros. Así, no se paralizó el crédito y se aseguró que los bancos dispusieran de los recursos para seguir financiando la actividad económica.

Además, con el fin de reducir la volatilidad del tipo de cambio, el BCRP vendió moneda extranjera por 6843 millones de dólares. Ello fue posible porque desde 2006 el BCRP había comprado 23333 millones de dólares. Una vez que pasaron los momentos de fuerte turbulencia internacional, en febrero de 2009, se comenzó a reducir la tasa de interés de referencia. Si esta medida se hubiese dado antes se corría el grave riesgo de que las expectativas inflacionarias no bajaran, además de una posible crisis cambiaria y una contracción del crédito, pues en una economía dolarizada como la peruana, cualquier aumento brusco del tipo de cambio puede significar que las personas y empresas endeudadas en dólares no cumplan con sus obligaciones, con el consiguiente efecto recesivo en la economía.

Es así, que cuando se controlaron las expectativas inflacionarias y se disiparon las presiones alcistas sobre el tipo de cambio en marzo de 2009, el BCRP incrementó el ritmo de reducción de la tasa de interés de referencia a partir de abril, hasta llevarla al nivel actual de $1.25 \%$, históricamente la más baja y la segunda tasa menor de las economías emergentes. Desde julio de 2009 el BCRP ha realizado operaciones swap de intercambio de dólares por soles a plazos hasta un año, con el objetivo de abaratar el costo del fondeo 
en soles de las entidades financieras, en particular las dirigidas hacia las microfinanzas, y propiciar que las tasas de interés de los créditos en dicho segmento, bajen más rápido. (p. 82)

Bajo los escenarios de crisis de 1997 y 2008, se determina persistencia del efecto de "contagio económico" que afecta el crecimiento y desarrollo de países que no presentan fortaleza externa en sus variables macroeconómicas.

Para el caso peruano, las entidades que pertenecen al sistema financiero son reguladas y supervisadas por la Superintendencia de Banca, Seguros y AFP (SBS), Banco Central de Reserva del Perú (BCRP) y Superintendencia del Mercado de Valores (SMV), manteniendo la estabilidad financiera y monetaria del país mediante políticas económicas efectivas.

\subsection{Contexto actual de Perú}

Desde la perspectiva macroeconómica, Perú ha reducido su nivel de fortaleza externa debido a factores como: disminución de Reservas Internacionales Netas (RIN) respecto del Producto Bruto Interno (PBI), caída en los precios de los commodities (cobre, en particular) y expectativas menos positivas sobre la balanza comercial del 2018. Esto último debido a la guerra comercial entre Estados Unidos y China (y la Unión Europea), los cuales son los destinos principales de las exportaciones peruanas.

Por otro lado, según la clasificadora de riesgo Fitch Ratings (2018), Perú refleja una balanza pública y externa sostenible, con políticas macro en escenario de confianza y que genera estabilidad financiera. Dicha fortaleza presenta vulnerabilidades por la alta dependencia sobre commodities, dolarización financiera, bajos ingresos del gobierno (recaudación), así como bajos ingresos per cápita; por lo que, para dicha clasificadora, Perú mantiene la clasificación de BBB+. La calificación de Perú es A3 en Moody’s y BBB+ en Standard and Poor's S\&P.

A continuación, se presentan las variables macroeconómicas que reflejan la situación actual del país ante posibles choques externos:

- Producto Bruto Interno: Comprende la totalidad de ingresos por la producción de bienes y servicios del país. El crecimiento sostenido del PBI 
representa estabilidad y solidez económica. Esta sirve, en parte, para atenuar choques externos. Para Mankiw (2014), se define como el mejor indicador que mide el rendimiento de la economía; siendo su objetivo el de unificar el valor monetario del conjunto de actividades económicas en un período establecido. (p. 66)

Figura 6.2

Variación anual del Producto Bruto Interno de Perú (\%)

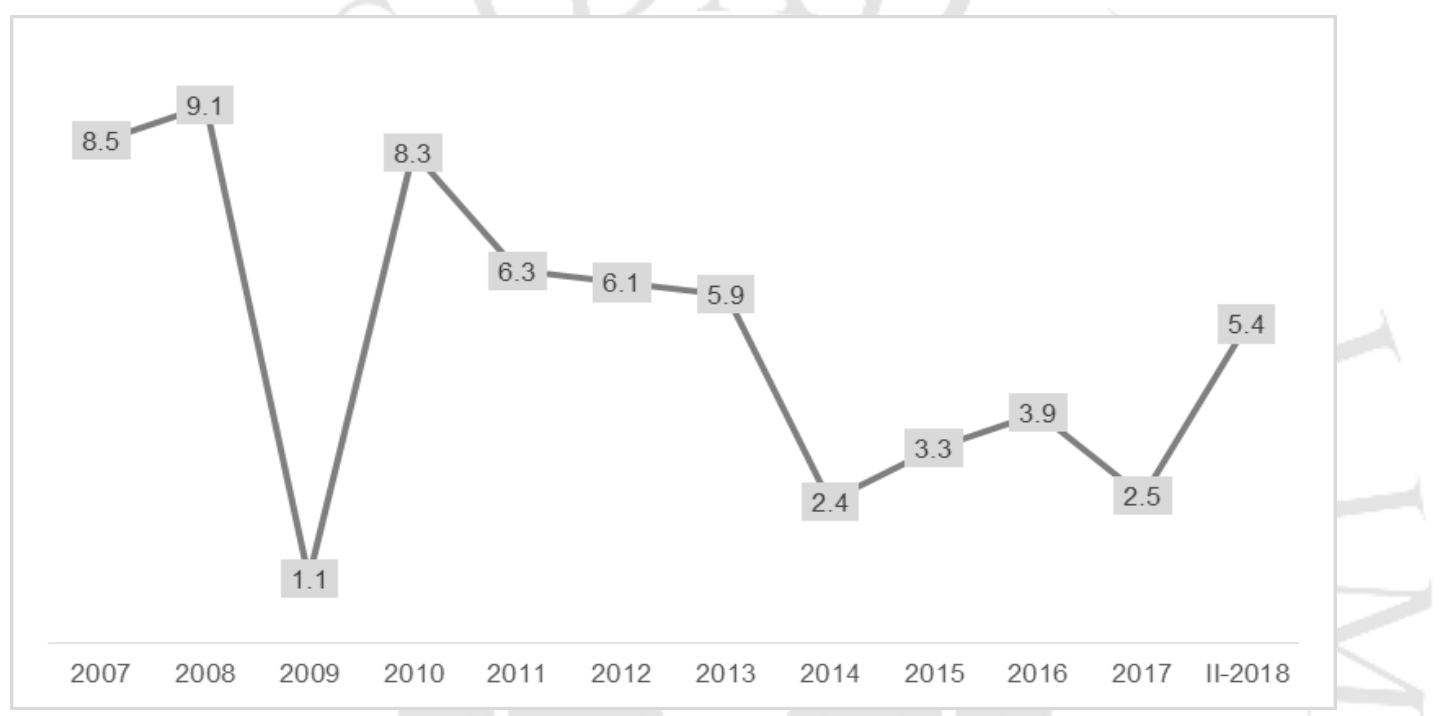

Fuente: Instituto Nacional de Estadísticas e Informática, INEI (2018)

- Reservas Internacionales: Compuesto por los activos en moneda extranjera, incluyendo el oro, bajo la administración del Banco Central. El FMI (2015) menciona que:

Ocupan un lugar importante entre los instrumentos de política económica de la mayoría de las economías. Sumadas a políticas sólidas, pueden contribuir a mitigar la probabilidad de crisis de balanza de pagos y preservar la estabilidad económica y financiera.

La relación entre la deuda de corto plazo y las reservas son fundamentales para evaluar la vulnerabilidad de un país. Según el BCRP (2018) en su Reporte de Inflación de setiembre, se identifica un alto nivel de reservas respecto a los países de Sudamérica que equivale a un nivel de hasta cuatro veces sus obligaciones externas de corto plazo. 
La reducción de aproximadamente tres millones de dólares de diciembre 2017 a junio 2018 se debe principalmente a una irregular salida de capitales de corto plazo, impactando sobre la cuenta financiera.

Figura 6.3

Evolución de las Reservas Internacionales Netas de Perú (Millones de dólares)

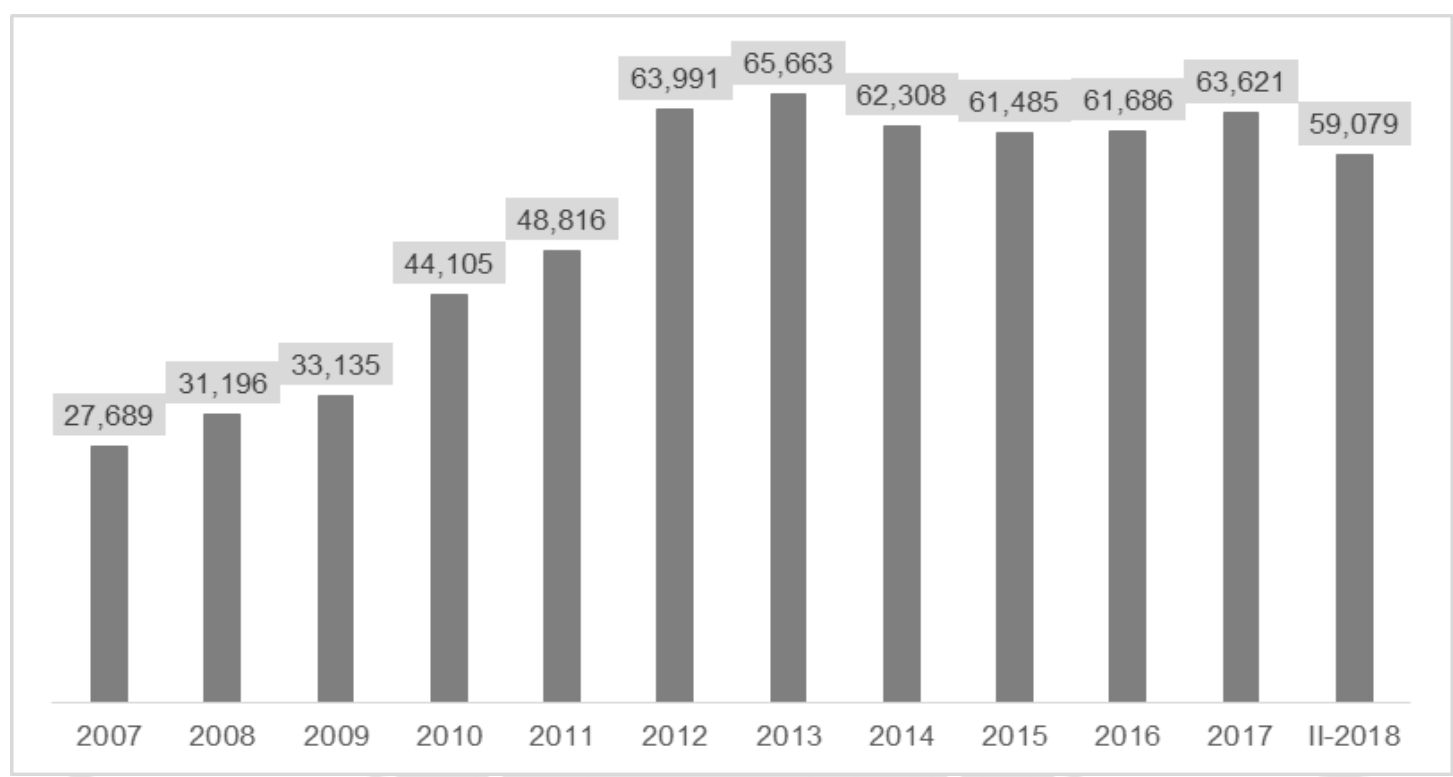

Fuente: Banco Central de Reserva del Perú, BCRP (2018)

Por otro lado, se presentan las reservas internacionales como razón sobre el PBI al 2017 para medir el nivel de liquidez que mantiene la economía respecto de los ingresos de modo comparativo con otros países de Sudamérica. También, esta razón identifica estabilidad económica y financiera ante choques externos. 
Figura 6.4

Reservas Internacionales Netas respecto del PBI de Sudamérica, 2017 (\%)

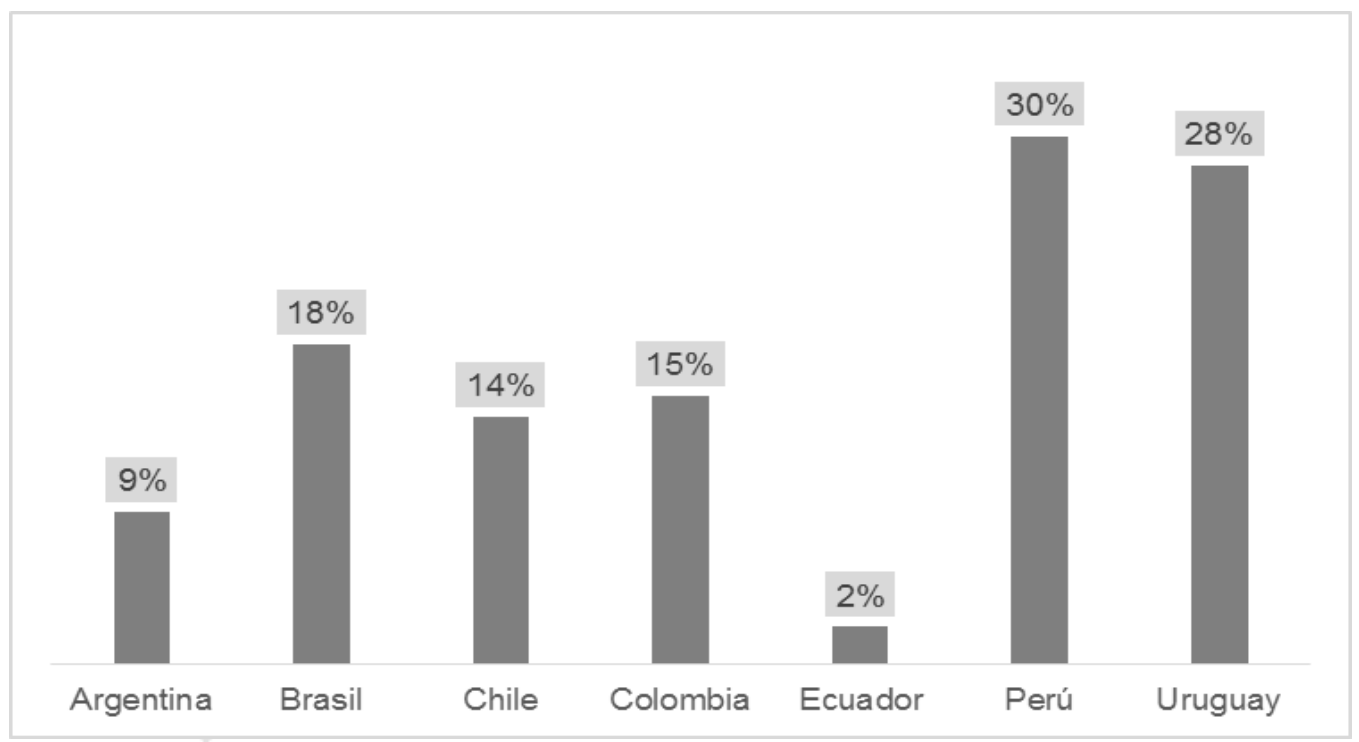

Fuente: Bloomberg (2018)

- Resultado Económico del Sector Público no Financiero: compuesto por la diferencia entre ingresos mediante recaudación (ingresos no financieros) del gobierno y los gastos incurridos del mismo. El BCRP, en su glosario de términos económicos, denomina "superávit o déficit fiscal según la diferencia sea positiva o negativa, respectivamente". Será empleada como razón sobre el PBI en la medición de eficiencia de la política fiscal sobre el ahorro del gobierno. Durante los primeros días de octubre, el BCRP (2018) indicó:

El déficit fiscal del Perú acumulado en los últimos 12 meses se redujo en setiembre de este año a $2 \%$ del producto bruto interno (PBI), menor en 0.1 puntos porcentuales respecto al registrado al mes anterior, debido a los mayores ingresos corrientes, que aumentaron de $19.2 \%$ a $19.4 \%$ del producto, mientras que los gastos no financieros se mantuvieron en $20.1 \%$ del PBI.

Adicionalmente, el MEF (2017) mantiene proyecciones hasta el 2021 de incremento en los ingresos tributarios para el déficit hasta llegar a un superávit de $1 \%$ respecto del PBI.

Se presenta la Figura 6.5, en la que hace referencia a la variación de déficit fiscal; que es financiado a través de la deuda pública (interna o externa). 
Figura 6.5

Evolución del Resultado Económico del Sector Público no Financiero respecto del PBI $(\%)$

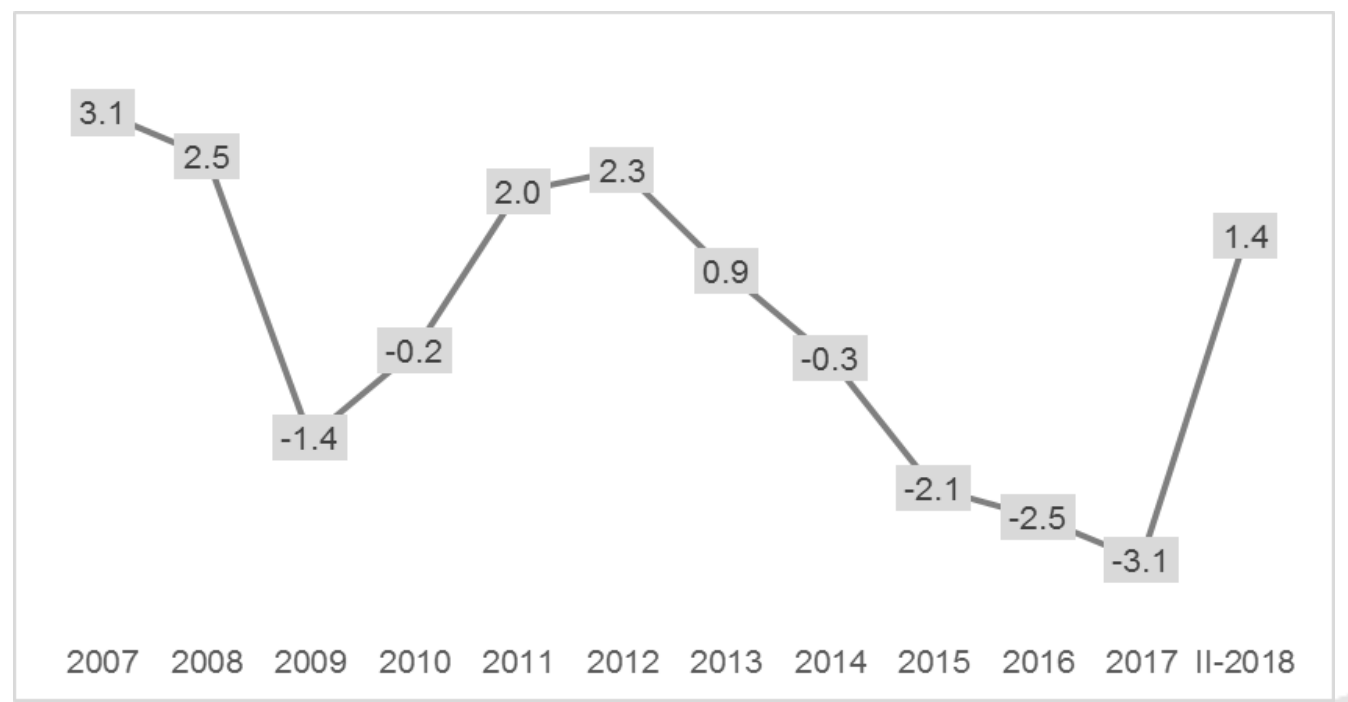

Fuente: Banco Central de Reserva del Perú, BCRP (2018)

Desde la perspectiva macroprudencial, el sistema financiero se mantiene estable, según el Reporte de Estabilidad Financiera elaborado por el BCRP en mayo (2018):

i. La mayoría de las entidades financieras reforzó sus niveles de solvencia y efectuó ajustes en sus gastos financieros y operativos para atenuar los efectos de la mayor morosidad sobre la rentabilidad.

ii. De esta forma, el sistema financiero ha afrontado con holgura los efectos negativos del aumento de la morosidad. De acuerdo a las pruebas de estrés realizadas, ante un eventual escenario macroeconómico adverso, la banca y las cajas municipales registrarían deterioros en sus indicadores financieros, aunque sin poner en riesgo su solvencia.

iii. El ratio de morosidad de los créditos del sistema financiero se elevó en los últimos doce meses, siendo los segmentos más afectados los de medianas empresas e hipotecario. El deterioro observado en la calidad de los créditos en general ha estado en línea con la evolución observada en la actividad económica en los últimos tres años. Tras la consolidación de las medidas correctivas implementas en las políticas crediticias de las entidades, se observa una recuperación en el crecimiento de los créditos. (p. 7)

En la Figura 6.6, se presenta la estructura del sistema financiero por activos, créditos y depósitos. A agosto de 2018, la participación por números de entidades es: 
bancos (16) - 83\%, empresas financieras (11) - 3\%, Cajas Municipales (12) - 6\%, Cajas Rurales (6) - 1\%, EDPYME (9) - 1\%, empresas de arrendamiento financiero (1) - $0.5 \%$, Banco de la Nación (1) - 5\% y Banco Agropecuario (1) - 0.5\%.

Como se aprecia, la mayor participación sobre el sistema financiero pertenece a los bancos; ya que componen el $83 \%$ de los activos, $86 \%$ de las colocaciones y $82 \%$ de los depósitos. Por lo mencionado anteriormente sobre la importancia de los indicadores de bancos sobre la vulnerabilidad financiera; se considerará la data de los bancos por ser representativos del sistema.

Figura 6.6

Estructura del sistema financiero, según tipo de cuenta del balance (\%)

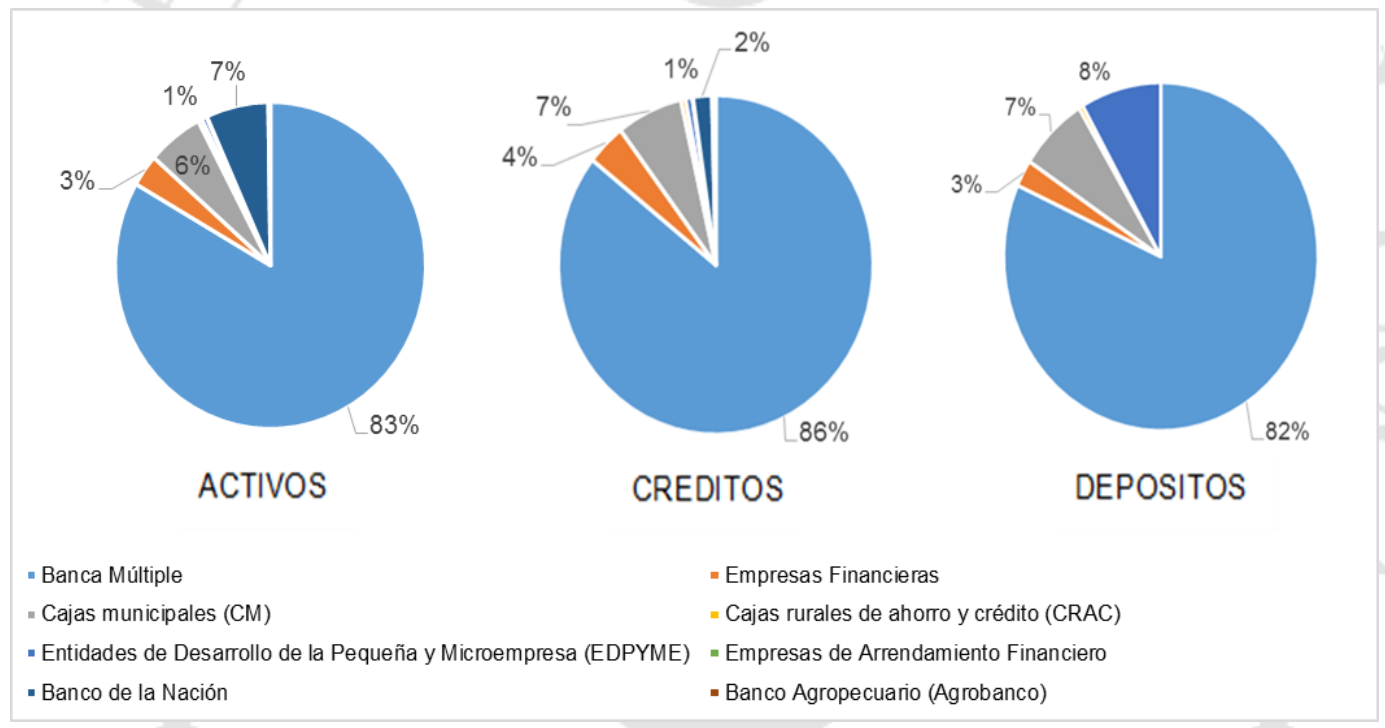

Fuente: Superintendencia de Banca, Seguros y AFP, SBS (2018)

\subsection{Variables consideradas en la medición de vulnerabilidad financiera}

Las variables que se toman en consideración para el modelo son las siguientes:

- Morosidad: Refleja la estructura de la cartera total de créditos. El cálculo de medición es el siguiente: $\quad \frac{\text { Cartera créditos vencidos }}{\text { Cartera total de créditos }}$

Asimismo, se presentan los siguientes criterios en la consideración para las carteras vencidas o con atrasos, según el Reporte de Estabilidad Financiera del BCRP de mayo (2018): 
En el Perú, se sigue un criterio más conservador de morosidad que en los demás países de América Latina. Así, un crédito se considera vencido cuando tiene más de 15 días de atraso para los créditos corporativos, a grandes y a medianas empresas y más de 30 días para los créditos a pequeñas y microempresas. En el caso de los créditos hipotecarios y de consumo, se considera vencida la cuota con más de 30 días de atraso y el saldo a partir de 90 días de atraso. Asimismo, en el Perú, la cartera refinanciada, que considera los créditos que han registrado variaciones de plazo o monto del contrato original por dificultades en la capacidad de pago del deudor, también se suele incluir en los indicadores de morosidad. Esto último no es parte de los indicadores de morosidad que otros países reportan al compendio "International Financial Statistics" del FMI.” (p. 11)

A continuación, se muestra la evolución de la cartera atrasada del sistema bancario, según los estándares mencionados. Se observa un incremento en la tasa de morosidad durante los últimos 10 años. Según Alberto Morisaki (2018), gerente de Estudios Económicos de la Asociación de Bancos del Perú (Asbanc), este comportamiento se explica por el crecimiento económico moderado, el cual influye sobre la generación de empleo formal y esto, a su vez, detona el incumplimiento de pagos.

\section{Figura 6.7}

Nivel de morosidad del sistema bancario (Cartera de créditos atrasados / Total de créditos, \%)

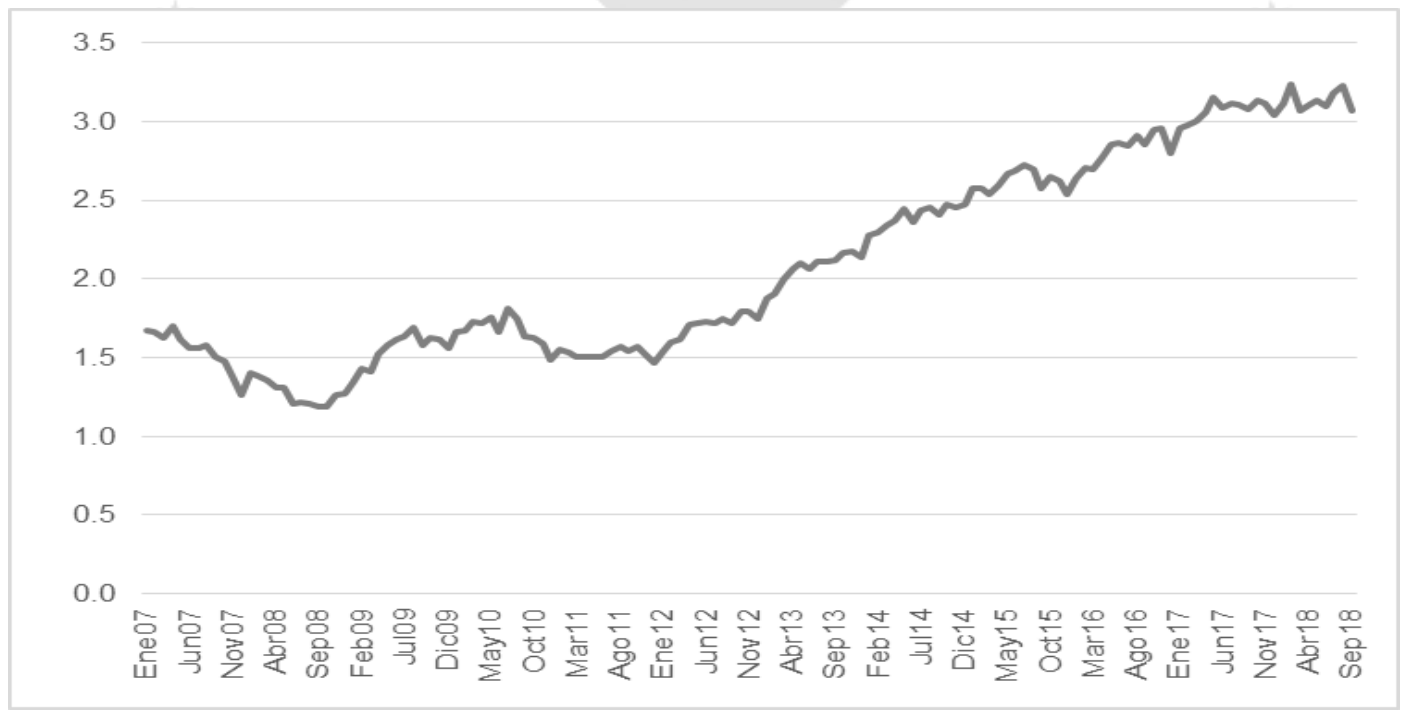

Fuente: Superintendencia de Banca, Seguros y AFP, SBS (2007 - 2018) 
Sin embargo, el BCRP (2017) en el Reporte de Estabilidad Financiera de noviembre, indicó que los bancos tomaron medidas correctivas en la política crediticia "tales como ajustes en los modelos de calificación de riesgo del deudor y fortalecimiento de sus áreas de negocios y de riesgos" (p. 8), a fin de mantener solidez en la cartera y evitar un peor escenario que el actual.

Cabe resaltar que, según Morisaki (2017), los bancos presentaron una acertada gestión del riesgo a fin de prevenir el deterioro en los créditos moratorios respecto de la cartera crediticia.

- Cobertura: Representa el nivel de provisiones que mantiene el sistema bancario ante el riesgo de posibles pérdidas sobre la cartera de créditos atrasados. El cálculo de dicho ratio es el siguiente: $\frac{\text { Provisiones constituidas }}{\text { Cartera créditos vencidos }}$

Como se observa en la Figura 6.8, durante la crisis del 2008, el índice de cobertura presenta un ligero incremento debido a que los bancos aumentaron el nivel de las provisiones como precaución ante cualquier choque externo que pudiera afectar los créditos atrasados (posible reducción en el nivel de empleo, de producto total, entre otros). A partir del 2011 se normalizó dicha situación, presentando una caída del ratio.

Figura 6.8

Grado de cobertura del sistema bancario (Provisiones constituidas / Cartera de créditos vencidos, \%)

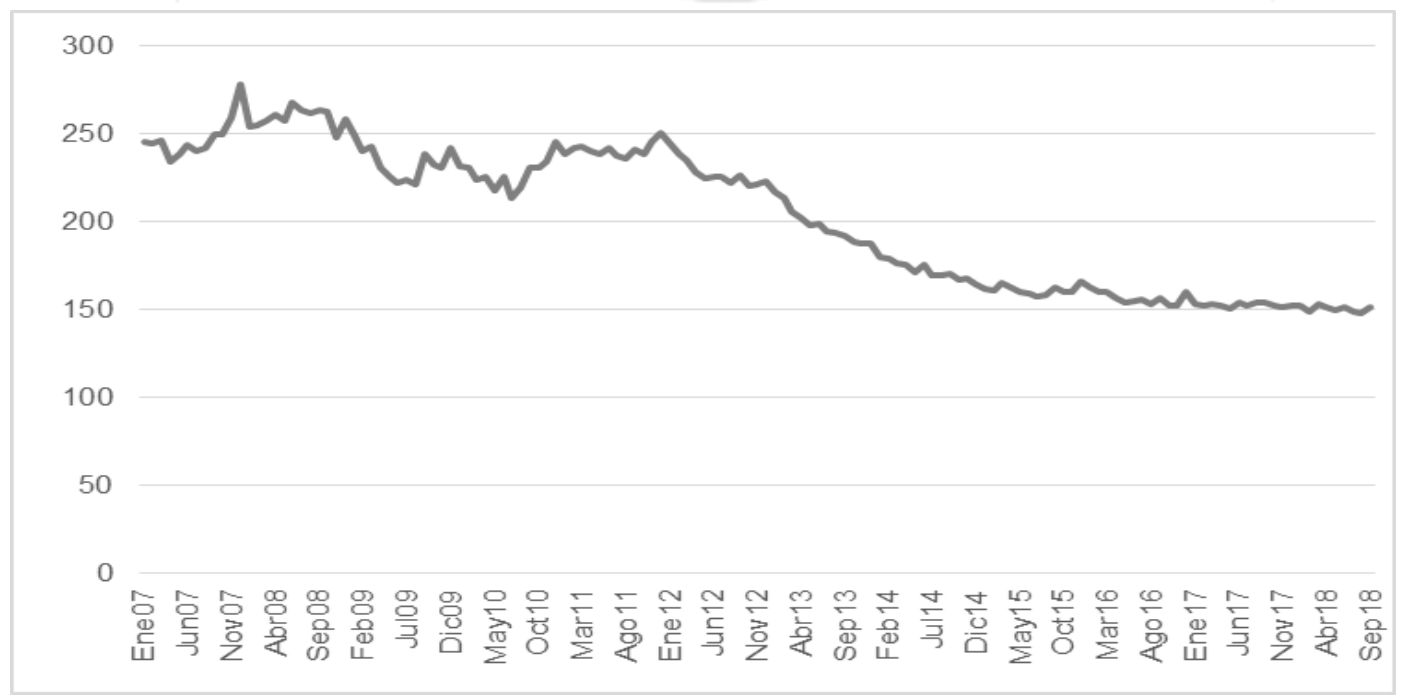

Fuente: Superintendencia de Banca, Seguros y AFP, SBS (2018) 
Sin embargo, a pesar del declive en el nivel de provisiones sobre la cartera de créditos atrasados, el ex presidente de Asbanc, Oscar Rivera (2017), sostuvo que el riesgo del sistema bancario peruano se encuentra dentro de los que presentan mayor cobertura:

"Si a ello le sumamos una cartera crediticia de alta calidad y holgados niveles de liquidez y capital por encima de los requerimientos nacionales e internacionales, estamos hablando de una gran solidez de nuestro sistema bancario".

Es importante indicar que, a pesar de que el nivel de cobertura se encuentre disminuyendo, la variable se encuentra por encima del mínimo requerido y exigido de $120 \%$ por la regulación.

- Variación de créditos en dólares: Representa la fluctuación de los créditos en moneda extranjera del sector bancario, y su comportamiento sobre las tasas de encaje en dólares, así como las tasas de referencia internacional determinadas por la Reserva Federal.

El cálculo de la variable es: $\frac{\Delta \text { Cartera de créditos } \mathrm{ME}_{\mathrm{t}-1, \mathrm{t}}}{\text { Cartera de créditos } \mathrm{ME}_{\mathrm{t}-1}}$

Los créditos se toman en moneda distinta a la nacional por dos principales motivos:

i). Por cobertura ante fluctuaciones del tipo de cambio, para poder afrontar operaciones en moneda extranjera.

ii). Por los ingresos en la misma moneda, para evitar riesgo cambiario sobre sus utilidades.

Por lo mencionado, los bancos determinan las tasas de interés en moneda extranjera a partir de: la tasa de encaje en dólares, determinada por el BCRP, mediante incrementos en las tasas de interés para reducir los créditos en dólares; y por la tasa de referencia internacional, impuesta por la FED. 
Figura 6.9

Variación de créditos en dólares del sistema bancario (\%)

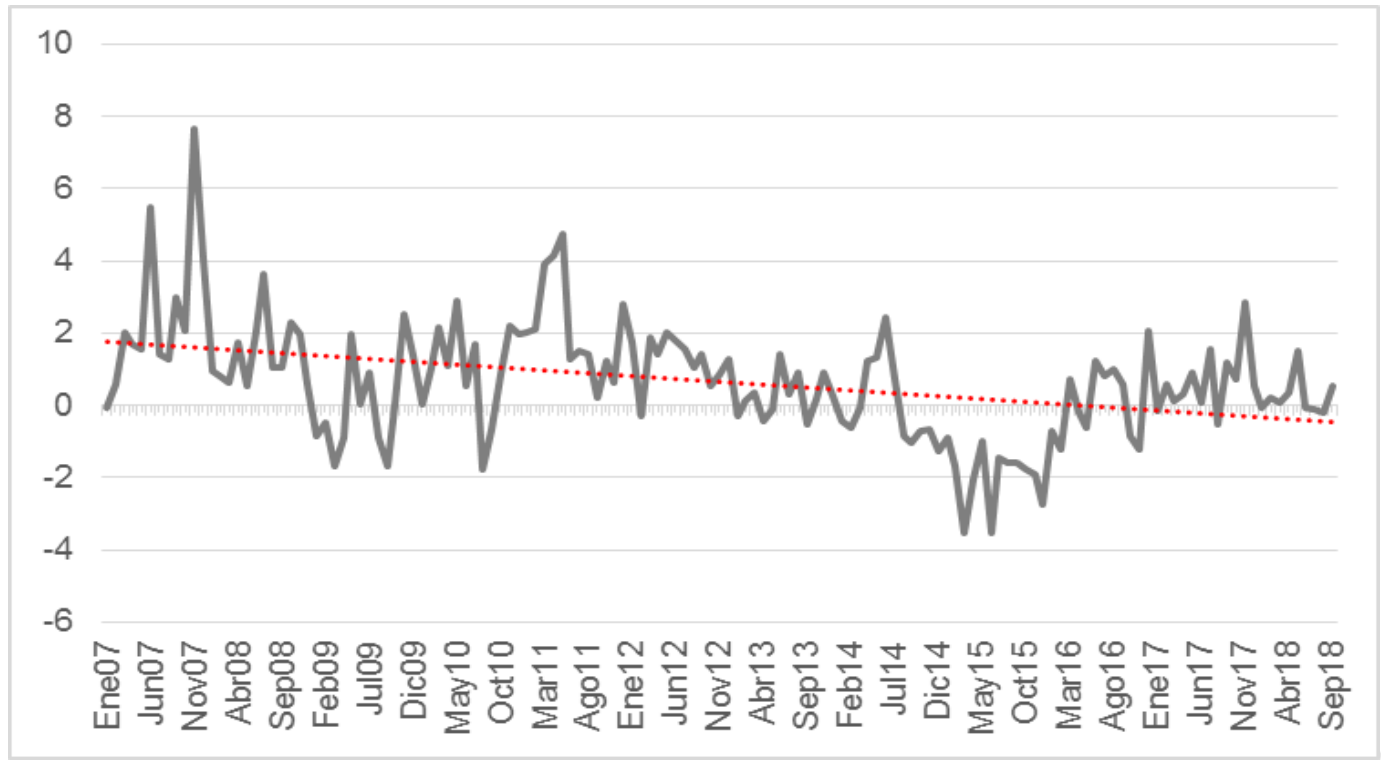

Fuente: Superintendencia de Banca, Seguros y AFP, SBS (2018)

- Variación de depósitos en dólares: Representa la variación de los depósitos en moneda extranjera del sector bancario, reflejando también el comportamiento de las tasas de encaje en dólares y las tasas de referencia internacionales determinadas por la Reserva Federal.

Los depósitos que se toman en consideración se encuentran compuestos por: depósitos a la vista, de ahorro, a plazo y de CTS.

El cálculo de la variable es a través de la siguiente ecuación:

$$
\frac{\Delta \text { Depósitos totales } \mathrm{ME}_{\mathrm{t}-1, \mathrm{t}}}{\text { Depósitos totales } \mathrm{ME}_{\mathrm{t}-1}}
$$

Los depósitos se realizan en moneda distinta a la nacional por dos principales motivos:

i). Por cobertura ante fluctuaciones del tipo de cambio, para poder afrontar operaciones en moneda extranjera.

ii). Por los ingresos en la misma moneda, para evitar riesgo cambiario sobre sus utilidades. 
Figura 6.10

Variación de depósitos en dólares del sistema bancario (\%)

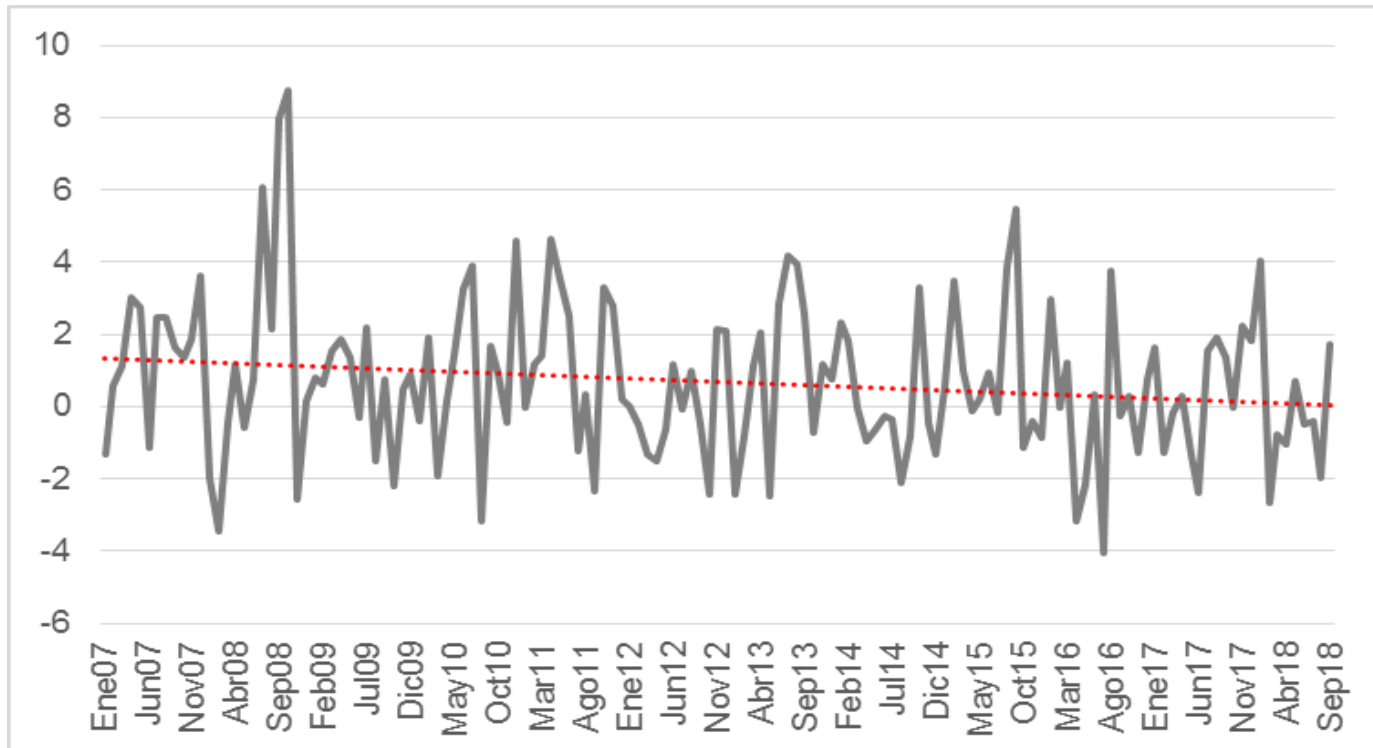

Fuente: Superintendencia de Banca, Seguros y AFP, SBS (2018)

- Nivel de Liquidez: Mide la capacidad de las entidades bancarias de afrontar requerimientos de fondos líquidos en el corto plazo debido al pago de sus obligaciones.

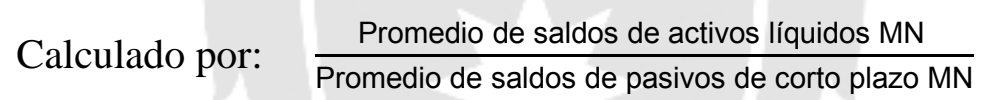

Donde, los activos líquidos se encuentran compuestos por: caja, fondos disponibles en el BCRP, fondos interbancarios netos activos, certificados de depósito y bancarios emitidos por empresas del sistema financiero nacional, del promedio mensual. Y los pasivos de corto plazo, son las deudas interbancarias, con entidades nacionales e internacionales, dentro del período de 1 año; también se trata del promedio mensual.

Como se observa en la Figura 6.11, el ratio de liquidez del sector bancario en Soles presenta una caída durante el 2008 y 2009, debido a la crisis de Estados Unidos.

El actual escenario estable del sector financiero peruano se sustenta en:

Una muestra de que se están tomando las medidas necesarias y que no hay ningún peligro de que se pueda dañar la economía nacional es que, a finales de enero de este año, el saldo de los préstamos totales otorgados por la banca alcanzó 232,640 
millones de Soles, monto que significó un crecimiento anual de 3.62\%, explicado por el avance de los créditos tanto en soles como en dólares. En ese sentido, reiteró que el sistema financiero tiene la liquidez suficiente para responder cualquier imprevisto. (Rivera, 2017)

\section{Figura 6.11}

Ratio de liquidez en moneda nacional del sistema bancario (Promedio de saldos activos líquidos en Soles / Promedio de saldos de pasivos de corto plazo en Soles, \%)

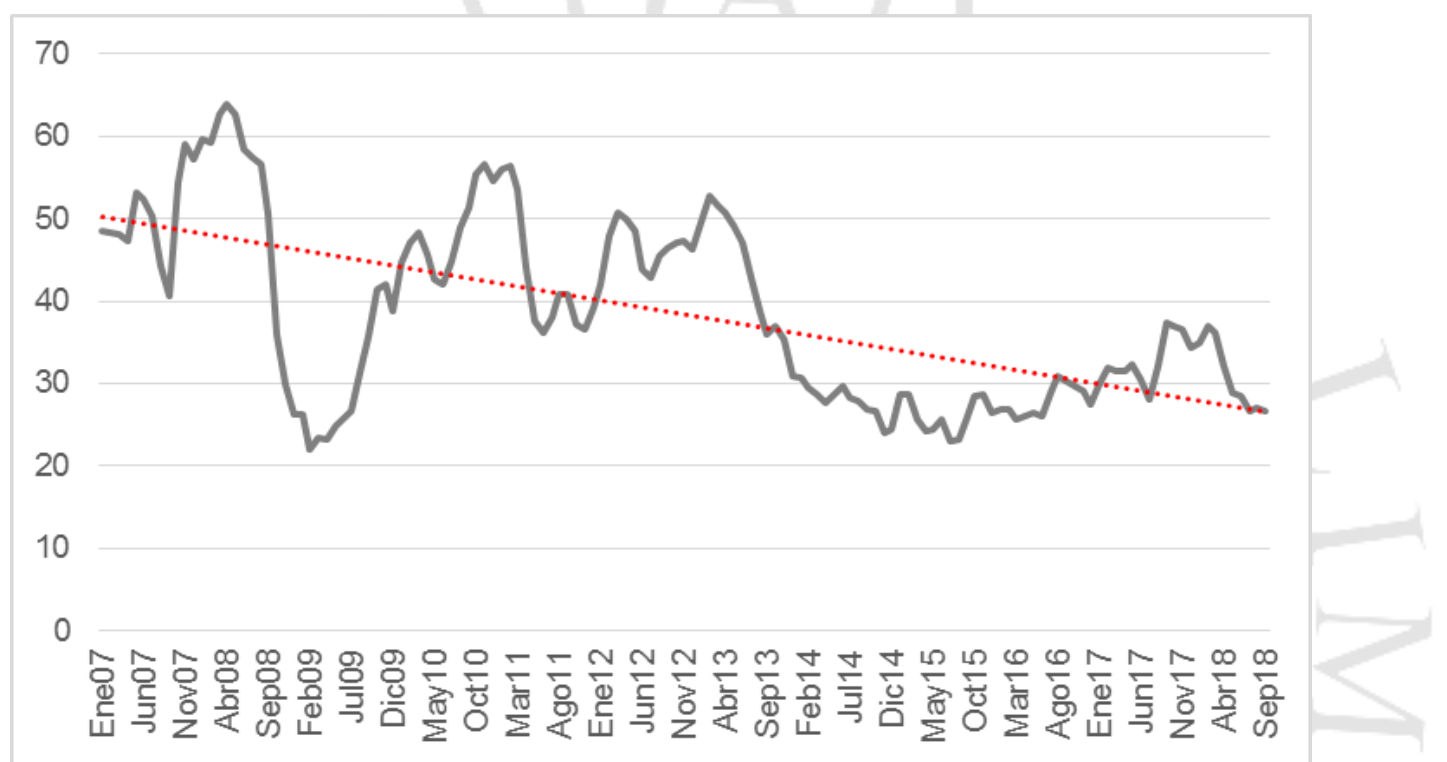

Fuente: Superintendencia de Banca, Seguros y AFP, SBS (2018)

- Nivel de Rentabilidad Patrimonial: Representa la utilidad de los accionistas (socios) a partir de los aportes al capital que estos realizan.

El ROE es una variable que refleja estabilidad, ya que ante choques negativos que puedan afectar a la banca, la rentabilidad es lo que mantiene sólida a la entidad y también como medición de eficiencia de recursos, como se menciona en el informe especial del BCRP (2007):

La rentabilidad de los bancos proviene de la realización de actividades ligadas a: posibilitar el acceso de los agentes económicos al sistema de pagos (reduciendo los costos de transacción al hacer más eficiente y menos oneroso el uso de los medios e instrumentos de pago, facilitando la movilidad de los recursos a bajo costo y riesgo); transformar activos (de sus depositantes, quienes esperan la continua disponibilidad de sus recursos, por uno de créditos demandado para consumo e hipotecario, y por empresas que buscan financiar proyectos de alto riesgo, de gran tamaño y de mayor 
plazo); manejar riesgos (de crédito, de tasa de interés y el de liquidez, asociados al manejo de los activos y pasivos, de mercado, de tipo de cambio y operacional); y, monitorear los proyectos desarrollados por sus prestatarios. (p. 44)

A continuación, se presenta la evolución del Return Over Equity (ROE) de los bancos, evidenciando un incremento considerable durante el período del 2008 2009, época de crisis financiera en Estados Unidos, que refleja la fortaleza de Perú ante dicha situación a nivel mundial.

Figura 6.12

Evolución de la rentabilidad sobre patrimonio de los bancos en Perú (Utilidad neta anualizada / Patrimonio promedio, \%)

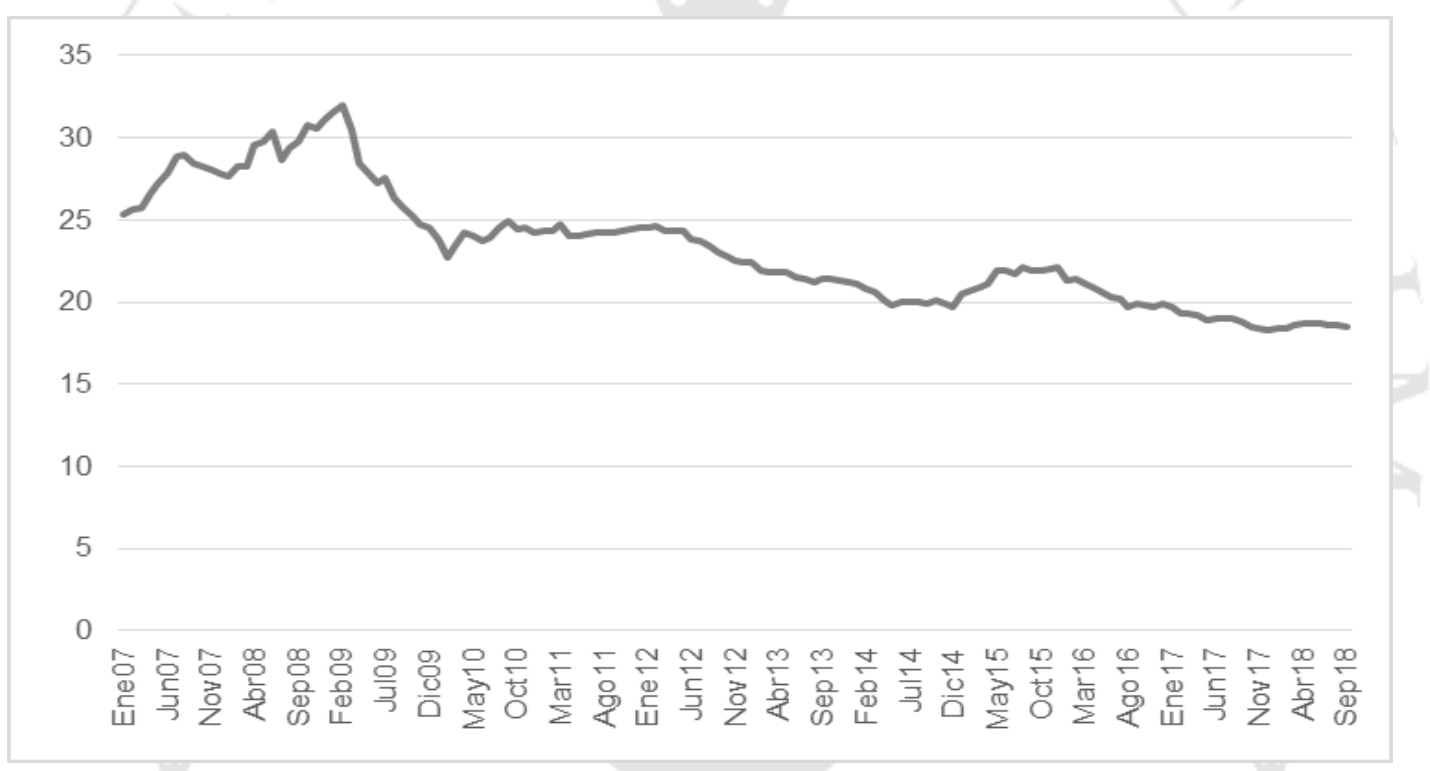

Fuente: Superintendencia de Banca, Seguros y AFP, SBS (2018)

Asbanc (2017) indicó que una variable que demuestra la responsabilidad con la que opera la industria bancaria es la que muestra el comportamiento del patrimonio de las empresas que conforman este sector. Lo que explica que la variable de Rentabilidad del patrimonio (ROE) continúe decreciendo, principalmente a través de incrementos del capital social y reservas, consolidando de esa manera la solidez de la banca. Asimismo, la variable parece decrecer debido a la competencia que existe entre las tasas de interés del mercado. 


\subsection{Marco macroprudencial}

\subsubsection{Regulación}

Basilea III: La propuesta se presentó como respuesta ante la crisis financiera mundial del 2008, para reforzar la gestión de riesgos de las entidades bancarias, y fortalecer la regulación financiera. Según lo publicado por la Superintendencia de Banca, Seguros y AFP (2015), se trata de que el sector bancario converja a los siguientes puntos: i) Mejorar la habilidad del sector bancario para absorber los shocks resultantes de un estrés económico o financiero, ii) Mejorar la gestión de riesgos y la gobernabilidad, iii) Fortalecer la transparencia de las entidades financieras y la publicación de información relevante. A continuación, los 3 pilares determinados por el Comité de Basilea:

- Pilar 1: Requerimientos mínimos de capital

- Pilar 2: Proceso de examen del supervisor

- Pilar 3: Disciplina del mercado

Adicionalmente, Basilea III tuvo la iniciativa de aplicar requerimientos mínimos de liquidez, lo cual comprende 2 nuevos ratios, ratio de cobertura de la liquidez (LCR) y ratio de financiación neta estable (NSFR), para atenuar los riesgos de liquidez al corto y largo plazo, respectivamente.

\subsubsection{Política monetaria}

- $\quad$ Tasa de Encaje en moneda extranjera: Para los bancos, existe un límite de grado de dolarización (medido por el BCRP a través de una tasa de encaje respecto de sus obligaciones). La tasa de encaje se utiliza para regular el ritmo de los créditos y la liquidez en moneda extranjera del sistema financiero. El BCRP ha podido reducir dicha tasa de encaje en dólares desde el 2016, a partir de una desaceleración del crédito y una política monetaria más restrictiva en los Estados Unidos. Actualmente, la tasa de encaje se mantiene en 35\%, desde junio de 2018, cuando el BCRP la redujo para inyectar US\$ 169 millones en el sistema financiero.

Desde la implementación del esquema de política monetaria de Metas Explícitas de Inflación (MEI) en el Perú, la dolarización financiera de la economía se ha reducido considerablemente, tanto a nivel de activos como de pasivos del sistema 
financiero. La dolarización de los préstamos disminuyó de 76.0 por cierto en enero de 2002 a 34.2 por ciento en junio de 2016, y la dolarización de los depósitos se redujo de 65.2 a 34.2 por ciento durante el mismo periodo.

Los principales factores que contribuyeron al proceso de desdolarización incluyen la sostenida estabilidad macroeconómica de la economía peruana reflejada en los niveles de inflación (dentro del rango de estabilidad de precios, con un promedio de 2.8 por ciento durante los últimos 15 años- y una gestión disciplinada de las cuentas fiscales -reflejada en una importante reducción de la deuda del sector público, que alcanzó un promedio del 29.6 por ciento del PBI durante el mismo período.

Además, el proceso de desdolarización se ha visto reforzado por políticas macroprudenciales encaminadas a fortalecer la estabilidad del sistema financiero, lo que permitió a las instituciones financieras internalizar los riesgos cambiarios, y por el desarrollo progresivo de los mercados de capitales con el comercio de activos en moneda nacional también desempeñó un papel importante. (Contreras, Quispe, Regalado, Martínez, 2017, p. 45)

- Tasas de Referencia: Es el principal instrumento de la política monetaria del BCRP, y utiliza para mantener la estabilidad monetaria; es decir, guiar la inflación hacia el rango meta. Esta tasa es modificada según las condiciones de la economía, hacia arriba o hacia abajo. Como se observa en la Figura 6.13, el BCRP redujo la tasa de referencia durante la crisis del 2008 como medida de incentivo en la estabilidad de los créditos de corto plazo, para garantizar la liquidez y que el sector financiero y la economía en general no se contrajeran. Cabe resaltar, que la reducción de la tasa de referencia se dio cuando los riesgos inflacionarios de inicios del 2009 se desvanecieron, y para entonces la inflación esperada se mantenía anclada dentro del rango meta. 
Figura 6.13

Evolución de la Tasa de Referencia de la política monetaria del BCRP (\%)

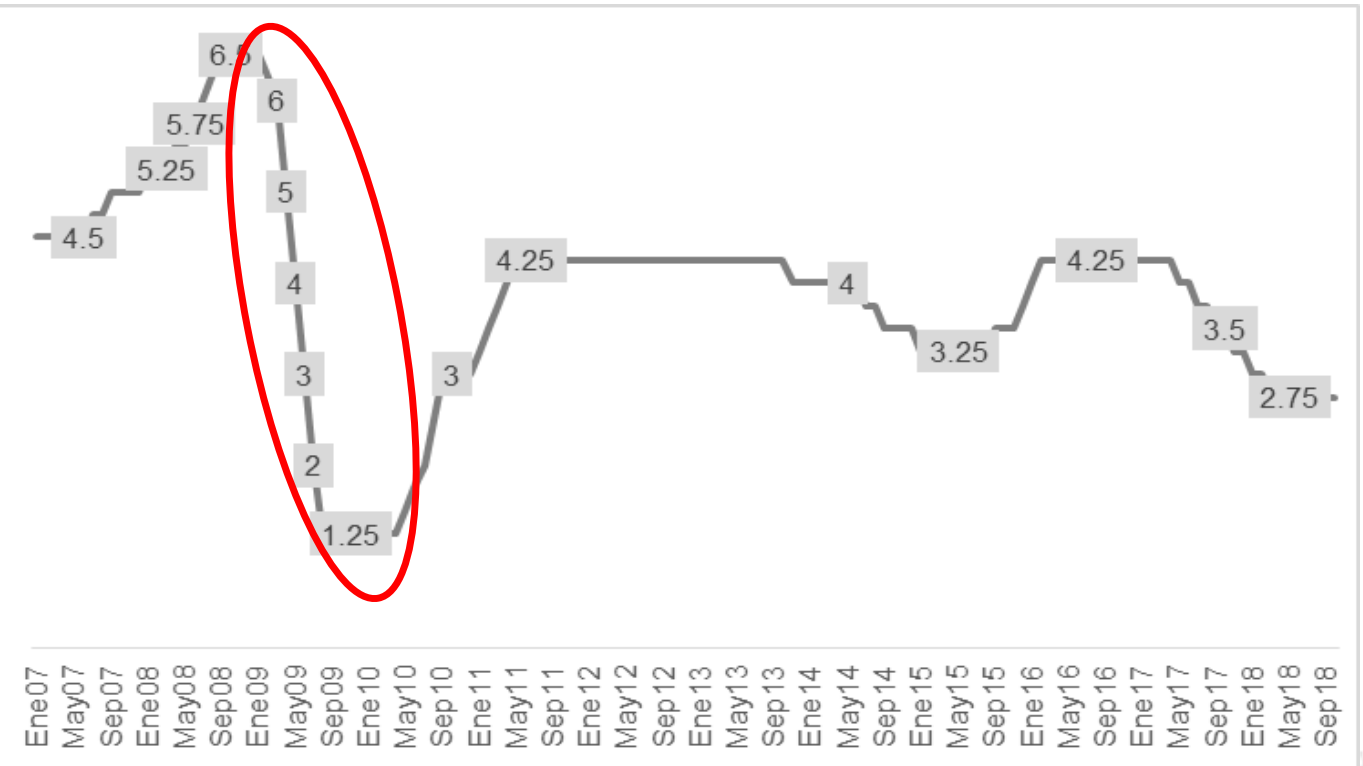

Fuente: Banco Central de Reserva del Perú, BCRP (2018) 


\section{ANÁLISIS Y DISCUSIÓN DE RESULTADOS}

Los resultados obtenidos a partir del modelo especificado son los siguientes (ver cuadro completo en Anexo 7.1):

\section{Tabla 7.1}

Resultado del modelo econométrico
\begin{tabular}{|cr|}
\hline Dependent Variable: VUL_FIN & \\
Sample: 2007M01 2018M09 & Coefficient \\
\hline Variable & -56.80926 \\
C & 15.63941 \\
MORA & -0.018549 \\
COBER & 0.719474 \\
VAR_CRED_ME & 0.849824 \\
VAR_DEP_ME & -0.291635 \\
LIQ_MN & 1.454513 \\
ROEA & 0.859153 \\
\hline McFadden R-squared &
\end{tabular}

Elaboración propia.

Donde se obtuvo el $\mathrm{R}^{2}$ de McFadden de 0.8591; que indica que las variables son significativas sobre el modelo que evalúa la vulnerabilidad financiera.

Las variables presentaron los siguientes signos y coeficientes, que serán explicados a continuación:

- $\widehat{\beta}_{1}$ : La morosidad presenta un coeficiente positivo de 15.64 , que implica relación directa con el indicador de vulnerabilidad financiera. La relación positiva está explicada por que, ante el incremento en el nivel de morosidad, existe un mayor riesgo de vulnerabilidad financiera. El resultado se encuentra asociado a la relación esperada, ya que un aumento en el incumplimiento de pagos de los créditos (cartera atrasada), se esperaría que el sistema bancario se encuentre ante un mayor nivel de vulnerabilidad.

- $\widehat{\beta}_{2}$ : El nivel de cobertura (provisión/cartera atrasada) del sector bancario presenta coeficiente negativo de 0.02 , que implica relación inversa sobre la vulnerabilidad financiera. Se mantiene la relación esperada inicialmente explicada por qué a mayor nivel de cobertura de los bancos, menor es el riesgo de ocurrencia de una crisis debido al grado de protección ante créditos atrasados.

- $\widehat{\beta}_{3}$ : La variación de créditos en moneda extranjera de los bancos presenta coeficiente positivo de 0.72 , que implica relación directa con el riesgo de crisis. La 
relación positiva se asocia a la esperada, ya que, ante un aumento en la fluctuación de los créditos en dólares, sea por el incremento o caída de los créditos en dicha moneda, el sistema bancario se encuentra expuesto a mayor riesgo de vulnerabilidad por exposición de riesgo cambiario.

- $\widehat{\beta}_{4}$ : Se obtuvo coeficiente positivo de 0.85 para la variación de los depósitos en moneda extranjera del sector bancario sobre la probabilidad de crisis, compatible con la relación esperada. Esto significa que, ante un aumento en la fluctuación de los depósitos en dólares, sea por incremento o fuga de depósitos, el sistema bancario se encuentra expuesto a mayor riesgo de vulnerabilidad para afrontar la exposición bancaria en dicha moneda, por tipo de riesgo cambiario.

- $\widehat{\beta}_{5}$ : El nivel de liquidez del sector bancario presenta coeficiente negativo de 0.29 sobre el indicador de vulnerabilidad financiera. Lo que refleja la relación inversa esperada que implica que, ante mayor nivel de liquidez, se reduce el riesgo de crisis ya que puede afrontar sus obligaciones del corto plazo.

- $\widehat{\beta}_{6}$ : Se presenta coeficiente positivo de 1.45 en la rentabilidad patrimonial del sector bancario sobre la probabilidad de crisis. No se esperaba dicho resultado ya que normalmente se refleja una relación negativa (a menor rentabilidad, mayor vulnerabilidad y viceversa). Sin embargo, el contexto actual de competitividad en las tasas de interés entre los bancos explica dicho resultado. Ante ese escenario, los bancos asumen mayor riesgo para poder nivelar la rentabilidad mediante más colocaciones.

La competitividad de tasas de interés mencionada en el sistema financiero se explica, también, por el incremento del número de las Fintech como plataforma opcional para utilizar los servicios financieros a través de la tecnología, tal como lo menciona Morisaki (2018):

"Mientras más entidades financieras aparezcan y den productos tanto de financiamiento a empresas y personas, la competencia te lleva a la disminución de tasas de interés y al final el beneficiado es el consumidor".

Finalmente, se utilizaron las variables mencionadas con sus respectivos coeficientes para construir el índice de vulnerabilidad financiera; que toma valores dentro del rango de 0 y 1 ; para lo cual, se tiene un valor de corte de 0.5 . Por debajo a dicho valor, 
implica no ocurrencia de vulnerabilidad; y por encima de 0.5 , sí existe ocurrencia del evento.

Figura 7.1

Indicador de vulnerabilidad financiera

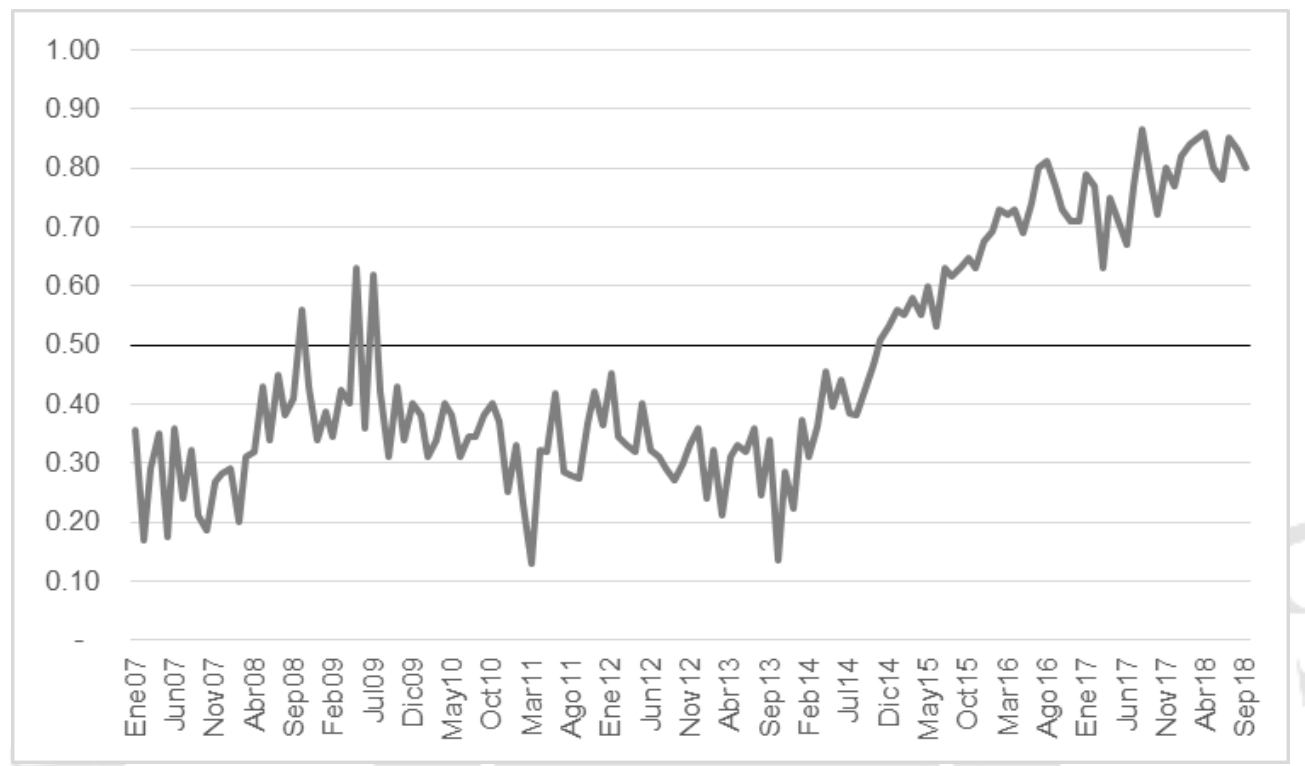

Elaboración propia.

Fuente: Superintendencia de Banca, Seguros y AFP, SBS (2018)

El indicador de vulnerabilidad financiera calculado bajo los parámetros indicados, mantiene tendencia creciente, debido a las fluctuaciones de las variables tales como incremento en el nivel de morosidad, caída en el ratio de cobertura, aumento en las variaciones de créditos y depósitos en dólares, caída en el nivel de liquidez en soles y de rentabilidad en los bancos.

Además, se obtuvo el siguiente resultado de predicción (ver cuadro completo en Anexo 7.2). El modelo estima de manera correcta 89 de las 91 predicciones de novulnerabilidad y 46 de las 50 predicciones de vulnerabilidad. Esto significa un $95.74 \%$ de predicción correcta sobre las variables; dentro del umbral de 0.5 (valor de corte); lo cual implica un $95.74 \%$ de exactitud del cálculo del indicador respecto de la medición de las variables empleadas.

Asimismo, el modelo acertó en sus predicciones sobre el indicador de novulnerabilidad en un $97.8 \%$, y en un $92 \%$ sobre el indicador de vulnerabilidad financiera como se muestra en la tabla 7.2. 
Tabla 7.2

Resultado del modelo de predicción

\begin{tabular}{|crrr|}
\hline \multicolumn{5}{|c|}{ Expectation-Prediction Evaluation for Binary Specification } \\
Success cutoff: $C=0.5$ \\
\hline \multicolumn{4}{c}{ Estimated Equation } \\
& Dep=0 & Dep $=1$ & Total \\
\hline $\mathrm{P}(\mathrm{Dep}=1)<=C$ & 89 & 4 & 93 \\
$\mathrm{P}(\mathrm{Dep}=1)>C$ & 2 & 46 & 48 \\
Total & 91 & 50 & 141 \\
Correct & 89 & 46 & 135 \\
$\%$ Correct & 97.80 & 92.00 & 95.74 \\
$\%$ Incorrect & 2.20 & 8.00 & 4.26 \\
\hline
\end{tabular}

Elaboración propia. 


\section{RECOMENDACIONES}

A continuación, detallaremos las recomendaciones:

- A raíz de los resultados de este informe, aparece la necesidad de evaluar, también, la vulnerabilidad externa e interna, a partir de las variables macroeconómicas más importantes, para estimar la vulnerabilidad total del país.

- Dadas las recomendaciones de la Organización para la Cooperación y el Desarrollo Económicos (OCDE) y la Superintendencia de Banca, Seguros y AFP (SBS), en el sentido de incentivar el uso correcto y adecuado de los créditos, depósitos y demás instrumentos financieros, resulta sumamente importante profundizar en la educación financiera de la sociedad peruana. Por el alcance del presente informe, no se incluyó este tema como parte del análisis.

- Las entidades reguladoras de los mercados financieros peruanos podrían realizar un análisis con mayor profundidad sobre la trayectoria de la relación entre la rentabilidad de los bancos (ROE) y la vulnerabilidad financiera del sistema, para entender el porqué del cambio en el sentido de dicha relación e identificar si se debe a un factor del contexto actual del país (temporal) o si se trata de un cambio permanente y cuáles son las razones de tal cambio.

- Del mismo modo, las entidades reguladoras deberán observar y, según sea el caso, tomar acciones correctivas ante la nueva situación de la relación entre la rentabilidad de los bancos y la vulnerabilidad del sistema. Esto debido a que, de acuerdo con los resultados, un incremento en el nivel de permisibilidad riesgo de los bancos que buscaría equiparar sus niveles de rentabilidad produciría una menor vulnerabilidad, lo cual resulta contraintuitivo y podría generar una conducta no deseada por parte de los bancos.

- Dado el comportamiento del indicador consolidado calculado de vulnerabilidad y su tendencia creciente, los organismos reguladores y los policymarkers podrían trabajar en un indicador similar mejorado y con información más completa para tomar acciones sobre el aumento en los niveles de vulnerabilidad financiera. 
- Para que el seguimiento de este indicador de vulnerabilidad financiera consolidado calculado pueda ser más estandarizado en el mercado y sea aplicado para posteriores estudios y toma de decisiones por los agentes del mercado, las autoridades y entidades reguladoras podrían determinar los parámetros sobre los cuales debe trabajarse cualquier análisis sobre la vulnerabilidad financiera del mercado peruano, para obtener mejores grados de precisión sobre la estimación, ya que la prevención tiene un papel importante para evitar situaciones de crisis. 


\section{REFERENCIAS}

Aghevli, B. B. (Junio de 1999). La crisis de Asia: Causas y remedios. Finanzas \& Desarrollo, 36(2), 28-31. Recuperado del sitio de Internet del Fondo Monetario Internacional: https://www.imf.org/external/pubs/ft/fandd/spa/1999/06/pdf/ aghevli.pdf

Banco Central de Reserva del Perú (2007). Reporte de Estabilidad Financiera. Recuperado del sitio de Internet del Banco Central de Reserva del Perú: http://www.bcrp.gob.pe/docs/Publicaciones/Reporte-EstabilidadFinanciera/Reporte-Estabilidad-Financiera-2007-Junio.pdf

Banco Central de Reserva del Perú (2017). Reporte de Estabilidad Financiera. Recuperado del sitio de Internet del Banco Central de Reserva del Perú: http://www.bcrp.gob.pe/publicaciones/reporte-de-estabilidad-financiera/refnoviembre-2017.html

Banco Central de Reserva del Perú (2018). Resumen Informativo Semanal No 39. Recuperado del sitio de Internet del Banco Central de Reserva del Perú: http://www.bcrp.gob.pe/docs/Publicaciones/Nota-Semanal/2018/resumeninformativo-39-2018.pdf

Banco Central de Reserva del Perú. (2009). Reporte de inflación: Panorama actual y proyecciones macroeconómicas 2009-2011. Recuperado del sitio de Internet del Banco Central de Reserva del Perú: http://www.bcrp.gob.pe/docs/Publicaciones/ Reporte-Inflacion/2009/setiembre/Reporte-Inflacion-Setiembre-2009.pdf

Banco Central de Reserva del Perú. (2018). Reporte de Estabilidad Financiera. Recuperado del sitio de Internet del Banco Central de Reserva del Perú: http://www.bcrp.gob.pe/publicaciones/reporte-de-estabilidad-financiera/refnoviembre-2018.html

Banco de Desarrollo de América Latina. (2013). La educación financiera en América Latina y el Caribe: Situación actual y perspectivas. Recuperado del sitio de Internet de la Organización para la Cooperación y el Desarrollo Económicos: 
https://www.oecd.org/daf/fin/financial-education/OECD_CAF_Financial_ Education_Latin_AmericaES.pdf

Berges Lobera, Á., Manzano Romero, D., y Valero López, F. J. (2011). Sistema bancario y vulnerabilidad financiera. Información Comercial Española, 35-42. Recuperado de: http://www.revistasice.com/CachePDF/ICE_863_3542_BEC9B4650F5932C8F7714BBC0E25457F.pdf

Contreras, A., Quispe, Z., Regalado, F. y Martínez, M. (2017). Dolarización real en el Perú. Estudio Económicos(33), 43-55. Recuperado del sitio de Internet del Banco Central de Reserva del Perú: http://www.bcrp.gob.pe/publicaciones/ revista-estudios-economicos.html

de Rato y Figaredo, R. (agosto, 2007). Crecimiento económico y desarrollo del mercado financiero: Fortalecimiento de la integración. Tercer Congreso Internacional de Derivados y Mercado Financiero. Campos do Jordão, São Paulo, Brasil. Recuperado del sitio de Internet del Fondo Monetario Internacional: https://www.imf.org/es/News/Articles/2015/09/28/04/53/sp082207

Fondo Monetario Internacional. (2003). Indicadores de Vulnerabilidad. Recuperado del sitio de Internet del Fondo Monetario Internacional: https://www.imf.org/ external/np/exr/facts/spa/vuls.htm

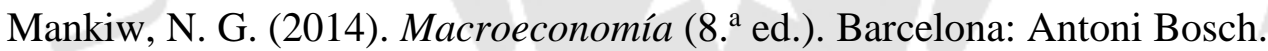

Ministerio de Economía y Finanzas (2017). Informe de actualización de proyecciones macroeconómicas. Recuperado del sitio de Internet del Ministerio de Economía y Finanzas: https://www.mef.gob.pe/contenidos/pol_econ/marco_macro/ informe_actualizacion_proyecciones.pdf

Morisaki, A. (6 de julio del 2018). Tasas de interés bajarían por mayor competencia entre entidades financieras y fintechs. Gestión. Recuperado de https://gestion.pe

Ordan, J., Melgar, M., y Rubio, C. (2010). Métodos estadísticos y econométricos en la empresa y para finanzas. Sevilla, España. Recuperado de http://libros.metabiblioteca.org/handle/001/362 
Peñaranda, C. (4 de octubre del 2018). Perú es la segunda economía en la región menos vulnerable a una crisis mundial. Cámara de Comercio de Lima. Recuperado de https://www.camaralima.org.pe/

Rivera, O. (2017). Sistema bancario peruano está sólido y listo para apoyar el crecimiento del país. Recuperado del sitio de Internet de la Asociación de Bancos del Perú: https://www.asbanc.com.pe

Rivera, O.(2017). Contexto internacional, economía y banca peruana. Departamento de Estudios Económicos. Lima: II Congreso Latinoamericano de Riesgo - CLAR 2017. Recuperado del sitio de Internet de la Asociación de Bancos del Perú: https://www.asbanc.com.pe/Publicaciones/Bolet\%C3\%ADn_Mensual_Septiem bre_2017.pdf

Superintendencia de Banca, Seguros y AFP (2017). Educación financiera: Empezando a formar consumidores responsables en los colegios. Recuperado del sitio de Internet de la Superintendencia de Banca, Seguros y AFP: http://www.sbs.gob.pe/Portals/0/jer/BOLETIN-SEMANAL/Boletin_Semanal_ N12.pdf

Superintendencia de Banca, Seguros y AFP (2018). Glosario. Recuperado de https://www.sbs.gob.pe/preguntas-frecuentes/id/3

Toribio, J. (2012). El contagio económico y financiero: Conceptos básicos. En F. Fernández Méndez de Andés, La crisis en Europa. ¿ un problema de deuda soberana o una crisis del euro? Madrid: Fundación de Estudios Financieros.

Wooldridge, J. (2010). Introducción a la econometría : un enfoque moderno (4. $\left.{ }^{\mathrm{a}} \mathrm{ed}.\right)$. (Reyes J., Ed., Hano Roa M., y Hernan E., Trads.) México, D.F.: Cengage Learning Editores, S.A de C.V. 


\section{BIBLIOGRAFÍA}

Allaín Cañote, L. D. (2006). Indicadores de vulnerabilidad financiera para los sistemas financieros en América Latina y aplicación para el caso peruano (Tesis de maestría). Lima: Universidad del Pacífico.

Wooldridge, J. M. (2010). Introducción a la econometría : un enfoque moderno (4. $\left.{ }^{\mathrm{a}} \mathrm{ed}.\right)$. (Reyes J., Ed., Hano Roa M., y Hernan E., Trads.) México, D.F.: Cengage Learning Editores, S.A de C.V. 


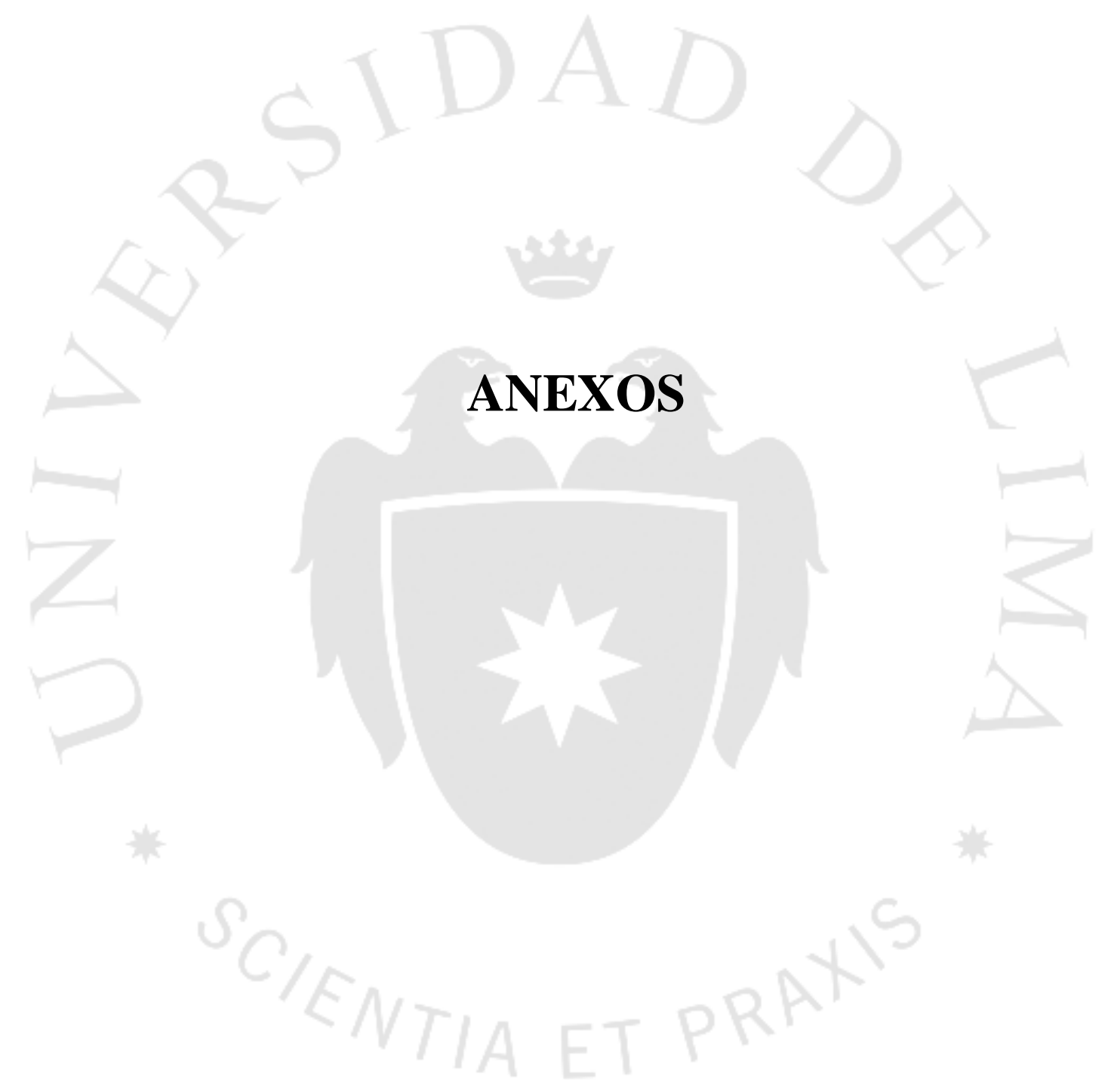




\section{Anexo 1: Resultado del modelo econométrico logit para la vulnerabilidad financiera}

Dependent Variable: VUL_FIN

Method: ML - Binary Logit (Newton-Raphson / Marquardt steps)

Sample: 2007M01 2018M09

Included observations: 141

Convergence achieved after 10 iterations

Coefficient covariance computed using observed Hessian

\begin{tabular}{crlrr}
\hline \hline Variable & Coefficient & Std. Error & z-Statistic & Prob. \\
\hline \hline C & -56.80926 & 48.30601 & -1.176029 & 0.2396 \\
MORA & 15.63941 & 10.66012 & 1.467094 & 0.1424 \\
COBER & -0.018549 & 0.210558 & -0.088094 & 0.9298 \\
VAR_CRED_ME & 0.719474 & 0.482714 & 1.490477 & 0.1361 \\
VAR_DEP_ME & 0.849824 & 0.394300 & 2.155271 & 0.0311 \\
LIQ_MN & -0.291635 & 0.258577 & -1.127845 & 0.2594 \\
ROEA & 1.454513 & 0.708149 & 2.053965 & 0.0400 \\
\hline \hline McFadden R-squared & 0.859153 & Mean dependent var & 0.354610 \\
S.D. dependent var & 0.480100 & S.E. of regression & 0.174721 \\
Akaike info criterion & 0.282463 & Sum squared resid & 4.090671 \\
Schwarz criterion & 0.428855 & Log likelihood & -12.91362 \\
Hannan-Quinn criter. & 0.341952 & Deviance & 25.82724 \\
Restr. deviance & 183.3716 & Restr. log likelihood & -91.68578 \\
LR statistic & 157.5443 & Avg. log likelihood & -0.091586 \\
Prob(LR statistic) & 0.000000 & & \\
\hline \hline
\end{tabular}




\section{Anexo 2: Resultado de la predicción de probabilidad de vulnerabilidad financiera}

\begin{tabular}{|c|c|c|c|c|c|c|}
\hline & \multicolumn{3}{|c|}{ Estimated Equation } & \multicolumn{3}{|c|}{ Constant Probability } \\
\hline & Dep=0 & Dep $=1$ & Total & Dep $=0$ & Dep=1 & Total \\
\hline$P(D e p=1)<=C$ & 89 & 4 & 93 & 91 & 50 & 141 \\
\hline$P(D e p=1)>C$ & 2 & 46 & 48 & 0 & 0 & 0 \\
\hline Total & 91 & 50 & 141 & 91 & 50 & 141 \\
\hline Correct & 89 & 46 & 135 & 91 & 0 & \\
\hline$\%$ Correct & 97.80 & 92.00 & 95.74 & 100.00 & 0.00 & 64.54 \\
\hline$\%$ Incorrect & 2.20 & 8.00 & 4.26 & 0.00 & 100.00 & 35.46 \\
\hline Total Gain* & -2.20 & 92.00 & 31.21 & & & \\
\hline \multirow[t]{3}{*}{ Percent Gain ${ }^{* *}$} & NA & 92.00 & 88.00 & & & \\
\hline & \multicolumn{3}{|c|}{ Estimated Equation } & \multicolumn{3}{|c|}{ Constant Probability } \\
\hline & Dep $=0$ & Dep $=1$ & Total & Dep $=0$ & Dep=1 & Total \\
\hline $\mathrm{E}(\#$ of Dep=0) & 87.02 & 3.98 & 91.00 & 58.73 & 32.27 & 91.00 \\
\hline $\mathrm{E}(\#$ of Dep=1) & 3.98 & 46.02 & 50.00 & 32.27 & 17.73 & 50.00 \\
\hline Total & 91.00 & 50.00 & 141.00 & 91.00 & 50.00 & 141.00 \\
\hline Correct & 87.02 & 46.02 & 133.03 & 58.73 & 17.73 & 76.46 \\
\hline$\%$ Correct & 95.62 & 92.03 & 94.35 & 64.54 & 35.46 & 54.23 \\
\hline$\%$ Incorrect & 4.38 & 7.97 & 5.65 & 35.46 & 64.54 & 45.77 \\
\hline Total Gain* & 31.08 & 56.57 & 40.12 & & & \\
\hline Percent Gain ${ }^{* *}$ & 87.65 & 87.65 & 87.65 & & & \\
\hline
\end{tabular}

${ }^{*}$ Change in "\% Correct" from default (constant probability) specification **Percent of incorrect (default) prediction corrected by equation 